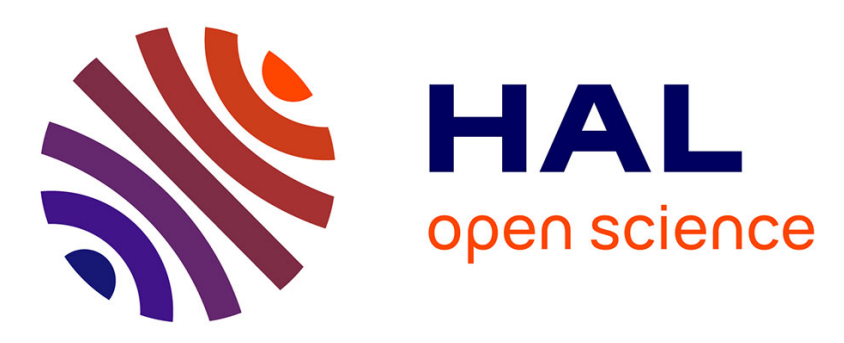

\title{
Identifying Salient Stressors of Adolescence: A Systematic Review and Content Analysis
}

Fernando Núñez-Regueiro, Santiago Núñez-Regueiro

\section{To cite this version:}

Fernando Núñez-Regueiro, Santiago Núñez-Regueiro. Identifying Salient Stressors of Adolescence: A Systematic Review and Content Analysis. Journal of Youth and Adolescence, 2021, 10.1007/s10964021-01492-2 . hal-03346400

\author{
HAL Id: hal-03346400 \\ https://hal.science/hal-03346400
}

Submitted on 16 Sep 2021

HAL is a multi-disciplinary open access archive for the deposit and dissemination of scientific research documents, whether they are published or not. The documents may come from teaching and research institutions in France or abroad, or from public or private research centers.
L'archive ouverte pluridisciplinaire HAL, est destinée au dépôt et à la diffusion de documents scientifiques de niveau recherche, publiés ou non, émanant des établissements d'enseignement et de recherche français ou étrangers, des laboratoires publics ou privés. 


\title{
Identifying Salient Stressors of Adolescence: A Systematic Review and Content Analysis
}

\author{
Fernando Núñez-Regueiro $\mathbb{1}^{1} \cdot$ Santiago Núñez-Regueiro $\mathbb{(}^{2}$
}

Received: 31 May 2021 / Accepted: 23 August 2021

(C) The Author(s), under exclusive licence to Springer Science+Business Media, LLC, part of Springer Nature 2021

\begin{abstract}
Stressors play a defining role in youth development and, in particular, in adolescent psychological and behavioral adaptation. However, the nature of stressors experienced during adolescence has not been reviewed or investigated comprehensively. To bridge this gap, this investigation conducted a systematic review of adolescent stressors reported in the literature (Study 1, $N=18$ studies) and a content analysis of self-reported stressors (Study 2, $N=1,568$ adolescents, Mean age $=15.5$ years, $41.5 \%$ female adolescents). The results converged in the identification of negative stressors (i.e., health issues, parental conflicts, issues with parents, teachers, peers or friends, romantic issues, concerns about the future and school) and positive stressors (i.e., leisure time, finding oneself, school or other accomplishments, social acquisitions, receiving help, romance and friendship, birth and good time in the family), which are highly occurring and highly intense among adolescents. Overall, these findings can guide researchers and practitioners towards developing efficient stressors measures, integrative theories on adolescent stress and development, as well as effective interventions targeting specific stress processes in the domains of education, criminology and psychopathology.
\end{abstract}

Keywords Stressors $\cdot$ Development $\cdot$ Adolescence $\cdot$ Systematic review $\cdot$ Content analysis

\section{Introduction}

Stressors have been defined as life experiences that disrupt the homeostatic fit between an individual and his or her environment, notably by inducing of a state of imbalance in transactions between the characteristics of the environment (e.g., demands, opportunities) and those of the individual (e.g., personal or social resources, psychological needs; Aldwin, 2007). Because they imply responding to environmental stimuli, stress processes play a central role in youth development, in ways that may be deleterious for

Supplementary information The online version contains supplementary material available at https://doi.org/10.1007/s10964021-01492-2.

$\triangle$ Fernando Núñez-Regueiro

fernando.nunez-regueiro@univ-grenoble-alpes.fr

1 Université Grenoble Alpes (LARAC), 1251 Avenue centrale, BP 47, 38040 Grenoble Cedex 9, France

2 Université de Picardie Jules Verne (CRIISEA)/Institut de Recherche pour le Développement (DIAL), 4 rue d'Enghien, 75010 Paris, France their adaptation to society. Across disciplines, theories have indeed linked youth stressors with psychopathology, school dropout or engagement in crime and delinquency (Dupéré et al., 2015). Research in this domain has nevertheless been plagued by measurement issues (Grant et al., 2014) and, in particular, little is known about the nature of stressors typically associated with the period of adolescence. As reported hereafter, more than a dozen studies have provided evidence on stressors by conducting interviews with adolescents or by asking them to take open-ended questionnaires, but only one study has described these stressors comprehensively across multiple domains of life (Burnett \& Fanshawe, 1997). Moreover, existing studies have used very diverse theoretical dimensions in their analyses (e.g., life domains, timing, occurrence, frequency, intensity, valence of stressors), thus limiting the emergence of a coherent and informative portrait of adolescent stressors. To address these limitations, the present research develops and uses a comprehensive analytical framework to identify the most "salient" stressors of adolescence-i.e., most commonly occurring and most intense stressors-in the empirical literature (Study 1, systematic review, $N=$ 18 studies) and in an original study sample (Study 2, content analysis, $N=1,568$ high school students). 
Fig. 1 Overview of adolescent stressors as a function of (a) developmental research traditions and (b) theoretical dimensions used in the present analytical framework

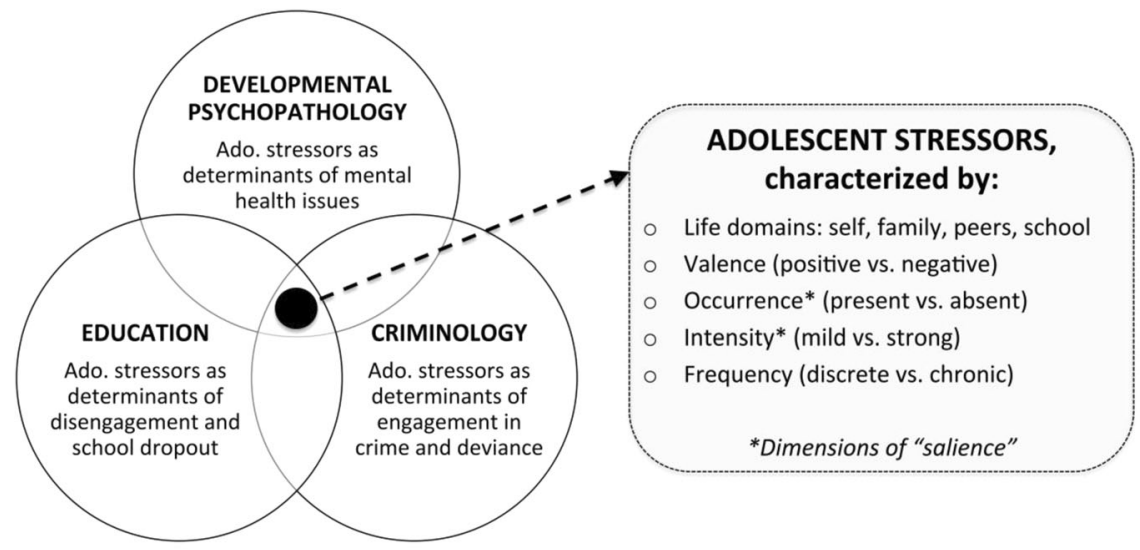

a) b)

\section{Stressors and Adolescent Development}

Across disciplines, adolescent stressors appear as common denominators of developmental theories. As is illustrated in Fig. 1a, research in the area of developmental psychology has repeatedly shown that events or conditions that pose a threat to adolescents' health or well-being (i.e., negative life experiences) contribute to the development of mental health issues, notably in the form of internalizing (e.g., depression, anxiety) and externalizing symptoms (e.g., aggression, delinquency; Grant et al., 2014). Relatedly, studies in criminology have underscored the importance of undesirable events or conditions (e.g., losing something good, receiving a bad treatment, failing to get something one wants) in explaining youth engagement in crime and social deviance, notably by instilling negative emotional states (Agnew \& Brezina, 2019). Likewise in educational research, studies have shown that exposure to severe life events or chronic difficulties facilitated high school dropout, by undermining student engagement (Dupéré et al., 2018). These commonalities between theories have received limited attention in the literature (for an exception, see Dupéré et al., 2015) but can be readily explained by the specific vulnerability of adolescence to stressors. Indeed, this developmental stage is characterized by a multiplicity of challenges - both demands and opportunities-associated with transitioning to new social roles as emerging adults, with emotional and behavioral changes (e.g., mood disruption, conflicts with parents, risky behavior; Arnett, 1999), but also psychophysiological changes in the developing teenage brain (e.g., heightened hormonal responses to stress that affect the psychological functioning; Romeo, 2013). The events and conditions experienced during adolescence are therefore crucial in explaining various developmental changes that have been studied in separate research traditions, but which share a common etiological framework (i.e., stressors as causes of development).
Despite their relevance, little is known about the kinds of stressors typically encountered by adolescents. This can be explained by certain limitations of past research, including a lack of consistency in measurement methods (e.g., no single measure has been used in more than 3\% of studies; Grant et al., 2014), a focus on single kinds of stressors (e.g., those most conducive to crime; Agnew \& Brezina, 2019) or, on the contrary, on multiple kinds of stressors considered cumulatively in scores of exposure to stress (Dupéré et al., 2018). As a result, studies in the area of stress processes have provided limited evidence on the relative prevalence of adolescent stressors (due to single stressors or cumulative stress scores) or on their characteristics (due to unsystematic dimensional ratings; see hereafter). Moreover, those studies that did provide some evidence on these issues, as presented in Study 1, mainly used it for scale development purposes (e.g., choosing relevant stressor items) and have not been systematically reviewed. To date, only one study has proposed to organize existing studies in a more comprehensive manner, by reviewing 11 stressors scales and by classifying each of their stressors as a function of three life domains: self, relationships and school (Burnett \& Fanshawe, 1997). This study thus provided a general overview of stressors commonly measured among adolescents in these specific life domains, but no data was extracted on other dimensions that could have provided a more precise description.

Although overlooked in past research, characterizing adolescent stressors further can provide useful information for research and intervention practices in the field. For example, this information can contribute to the development of more efficient and consistent measurement methods, by shedding light on the most relevant stressors of adolescence (e.g., the most salient stressors, as explained hereafter). Instead, existing methods lack specificity and dwell on exhaustive approaches by asking respondents to answer 
very long checklists of potential stressors (e.g., 100-item checklists) or to take hour-long semi-structured interviews, thus strongly limiting research feasibility (e.g., high rates of missing data, satisficing behavior, increased research costs and opacity; Núñez-Regueiro et al., 2021). Complementarily, this information can indicate which of the stressors most conducive to crime and delinquency (e.g., peer abuse, academic failure, negative relations with teachers, perceived excessive supervision from adults; Agnew \& Brezina, 2019) are most prevalent during adolescence, which could lead to a better understanding of the contextual sources of adolescent-limited offending-as opposed to psychosocial sources (e.g., social mimicry, maturity gap)and, by implication, of better-targeted interventions by practitioners (Moffitt, 2007). More generally, pinpointing salient adolescent stressors can guide research on youth heterogeneity, which is often associated with specific life experiences that, although common, may be specific to certain developmental profiles. For example, profiles of social attachment have been shown to differ in terms of social conflicts (e.g., parents, peers, romantic partners; Seiffge-Krenke, 2006), whereas profiles of school dropout revealed differences in the sources of stress that precipitated the decision to quit school (e.g., accidents, academic failure, workload, social conflicts; Lessard et al., 2008). In sum, there is a strong research need to describe adolescent stressors based on informative theoretical dimensions.

\section{Dimensions of Adolescent Stressors}

Life experiences qualify as stressors when their occurrence produces a state of imbalance in person-environment transactions, that results in negative or positive psychophysiological responses (i.e., "distress" and "eustress" responses, respectively; Branson et al., 2019) aimed at regaining a state of balance (Aldwin, 2007). This general definition applies to a variety of life experiences that may include traumas (e.g., accidents, physical assaults), chronic social roles (e.g., meeting expectations as a student, as a friend, as a romantic partner), major positive or negative life events (e.g., death or birth in the family, loss of job, onset of chronic illness), and daily uplifts and hassles (e.g., receiving a good or bad grade, being subject to critiques or compliments). Previous studies have sought to organize this diversity around theoretical dimensions such as the time and space of stressors (e.g., timing, life domains) and the qualities of exposure to stressors (e.g., occurrence, valence, frequency, intensity; for a review, see Núñez-Regueiro et al., 2021). For the present purpose, these theoretical dimensions offer analytical tools to describe the different kinds of stressors that adolescents may encounter in their lives and, in particular, those that are most often occurring and intense (see Fig. 1b).
Concerning the time-space dimensions of stressors, "timing" relates to the life stage of occurrence of a stressor (e.g., childhood, adolescence, adulthood), which concerns adolescence in the present case. The "life domains" refer to the spheres of life where a stressor is predominantly situated or relevant to (e.g., self, family, peers, school, society). Current (Núñez-Regueiro et al., 2021) and past research (Wheaton, 1994) has systematically shown that adolescent stressors concern multiple life domains.

Concerning the qualities of exposure to stressors, four dimensions are most relevant. First, "valence" is the dimension that describes whether the stressor was perceived by the individual as positive (or desirable) as opposed to negative (or undesirable), which can be used to differentiate stressors that have an ambivalent status from those that are systematically experienced as positive or negative, both in daily stressors (e.g., hassle vs. uplifts; Wu \& Lam, 1993) and in life stressors (positive vs. negative life events; Swearingen \& Cohen, 1985). "Occurrence" is a theoretical dimension that has been used to register the existence of a stressor (vs. absence), notably in protocols measuring cumulative stress (e.g., sum scores of total number of stressors encountered). Although this dimension may suffice to quantify the association of stressors with outcomes of interest, notably when combined with the dimension of valence (Núñez-Regueiro et al., 2021), other dimensions are needed to obtain a more qualitative understanding of stressors themselves. For instance, "frequency" describes stressors according to a continuum ranging from chronic situations that characterize a person's ordinary environment and which are usually low in intensity (recurring social roles or situations, such as attending classes, commuting to school, meeting with friends), to discrete events that seldom occur but which are intense enough to be noticeable by the individual (e.g., attending a major social event, being in a car accident, death or birth in the family; Wheaton, 1994). Chronic and discrete stressors appear to be related in reciprocal causalities, with chronic stressors arising from discrete ones (Masten et al., 1994), or conversely (Sandberg et al., 1993). Also, they are hardly differentiable a priori, meaning that their classification as discrete or chronic depends on individual experiences of stress (Turner \& Wheaton, 1997).

Finally, the dimension of "intensity" characterizes stressors in terms of their perceived impact or severity for the individual, which aligns with a cognitive-appraisal approach on stressful experiences (Lazarus \& Folkman, 1984). Because it focuses more specifically on describing low to high degrees of stressfulness, this dimension is perhaps the most relevant for distinguishing important from less important stressors in the lives of individuals and, in particular, in the lives of adolescents (Cheng, 1997). However, very intense stressors may have a very low 
Fig. 2 Search strategy for the systematic review (Study 1). Dotted arrows and boxes are based on a previous scoping review of stressors scales (Núñez-Regueiro et al., 2021)

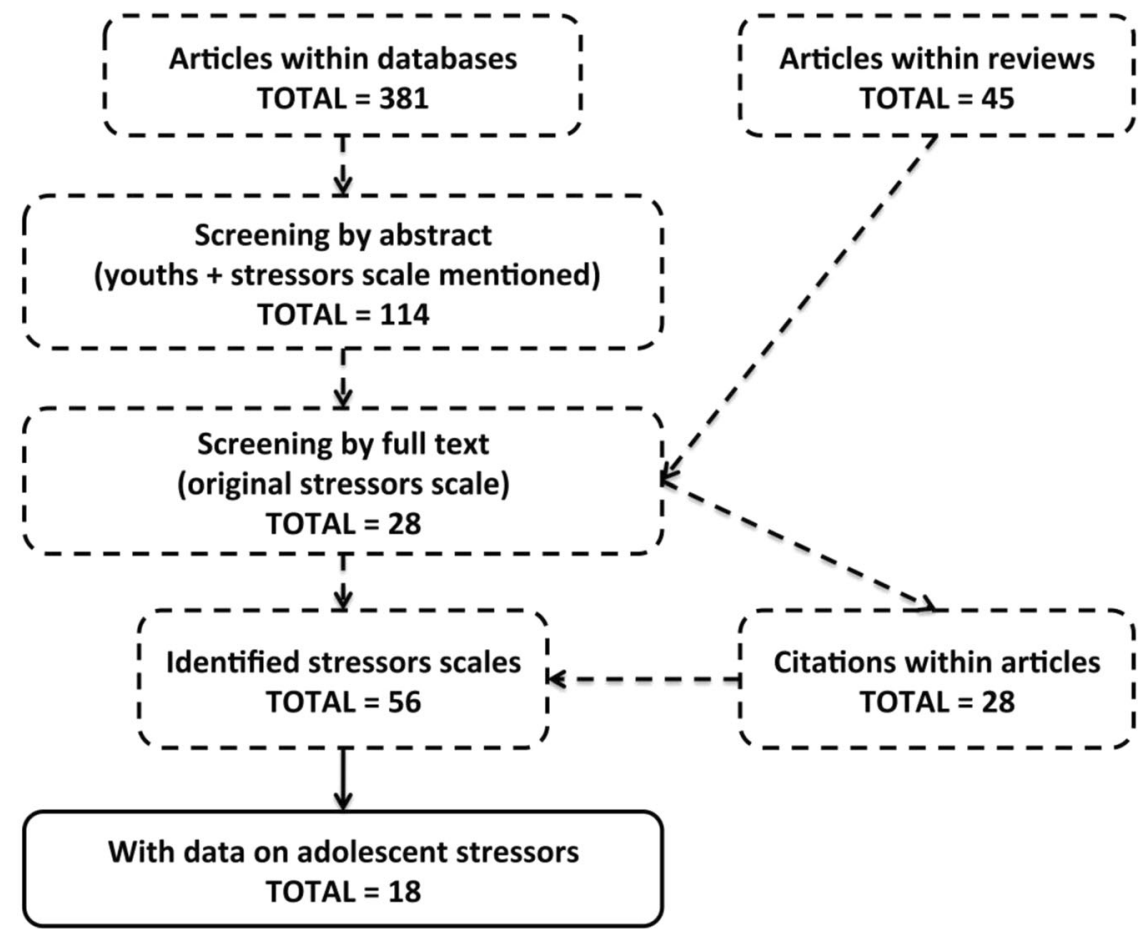

prevalence in the population (e.g., contracting an incurable and rare disease), which would limit their meaningfulness for most adolescents. In this perspective, the present systematic review and content analysis will focus on salient stressors that can be characterized both as intense and commonly occurring among adolescents, while also taking into account other dimensions (life domains, valence, frequency) for a more fine-grained depiction of these salient stressors.

\section{Study 1: A Systematic Review of Salient Adolescent Stressors}

Despite considerable research on youth stress (cf. Introduction), no study has offered to describe adolescent stressors according to systematic theoretical dimensions. Work by Burnett and Fanshawe (1997) compared the kinds of adolescent stressors reported in measurement methods and organized them by life domains, yet their analysis did not reach a comprehensive framework to synthesize the data on stressors. The present study complements this line of research by conducting a systematic review of adolescent stressors that focuses on the theoretical dimensions constitutive of salient stressors (i.e., occurrence and intensity), while also accounting for other relevant dimensions (i.e., life domains, valence, frequency). Although exploratory in nature, it is expected that the review will identify recurring themes that provide evidence for the existence of salient stressors.

\section{Method}

\section{Literature Search Strategy}

The systematic review builds on a recent scoping review of children and adolescent stressors scales (Núñez-Regueiro et al., 2021), which was used to extract data on adolescent stressors. Following PRISMA guidelines for identifying and screening relevant studies, the scoping review conducted a systematic literature search strategy (Arksey \& O'Malley, 2005; Moher et al., 2009) based on 7 literature reviews on stressors scales (Agurto \& Muñoz, 2015; Burnett \& Fanshawe, 1997; Compas, 1987; Grant et al., 2004; Matheny et al., 1993; Newcomb et al., 1981; Turner \& Wheaton, 1997) and 4 academic databases chosen for their diversity and relevance with the subject matter (i.e., Psychology and Behavioral Sciences Collection, APA PsycInfo, SocINDEX and Education Resources Information Center). Reviews and databases were screened to identify original stressors scales published in peer-reviewed journals between 1956-year of publication of Selye's seminal stress model (as cited in Wheaton, 1994) - and 2020 that included children and adolescent samples. As illustrated in Fig. 2, the literature search for the scoping review screened over 426 publications, which resulted in the identification of 56 studies containing original youth stressors scales. In the present review, the search strategy was carried forward in order to identify, among the 56 studies, those that also reported data on specific adolescent stressors. This filtering led to a total of 18 studies, after excluding studies that did not comprise 
adolescents (e.g., focus on children) or that did not report data on specific stressors (e.g., sum scores over all stressors).

The final selection of 18 studies (see Table 1) covers early to late adolescents across 6 countries or nations (i.e., Australia, Canada, Hong Kong, Netherlands, United Kingdom, United States of America). Four of these studies used a stratified or randomized surveying strategy to increase the representativeness of their samples (Alban Metcalfe et al., 1982; Byrne et al., 2007; Cheng, 1997; Lewis et al., 1984), and all but one study (Compas et al., 1987) used a modest $(N>150$ adolescents) to large sample $(N>1,000$ adolescents) to analyze adolescent stressors across relevant dimensions. Taken together, these studies provide information on stressors experienced by 10,017 adolescents or children (i.e., in a minority of cases, children aged 4 to 10 years old; Berden et al., 1990; Ham \& Larson, 1990; Masten et al., 1994; Yamamoto, 1979). The methods used to pool adolescent stressors differed across studies, with some privileging an expert-based approach (i.e., literature reviews, preexisting scales, authors' expertise) and others an adolescent-based approach (i.e., collective or individual interviews with adolescents). However, none of the adolescent-based studies (i.e., 10 out of 18 studies) reported their strategy for transforming self-reported experiences into categories of stressors, which might have differed for each author. Moreover, studies used various dimensions for rating stressors (i.e., occurrence, valence, intensity, frequency). These differences in practices thus result in very diverse and rich data on stressors (see columns 2 and 5 of Table 1).

\section{Data Extraction: Synthesizing the Evidence on Adolescent Stressors}

The next step in conducting the systematic review consisted in extracting and synthetizing qualitative and quantitative data on adolescent stressors from the selected studies. This required addressing three major difficulties. First, as could be expected from using different stressors scales, the denomination of adolescent stressors differed across studies and therefore required developing overarching categories to combine the data, while still preserving the specificity of each kind of stressors. For example, stressors denoting students' concerns about their career and educational plans or perspectives were grouped under the category of "concerns about the future". In total, 52 exhaustive and mutually exclusive categories were generated that offered a coherent framework to encode the data. As is apparent from Table 2, these categories were classified according to life domains (self, family, peers, school) and valence (positive vs. negative stressors), the classification of valence being based on studies that reported this dimension as well (Ham \&
Larson, 1990; Kanner et al., 1987; Masten et al., 1994; Newcomb et al., 1981; Swearingen \& Cohen, 1985). For transparency, the encoding of each specific denomination (i.e., in a given study) with its corresponding stressor category was registered in Online Resource 1.

Second, for each category of stressors, the goal was to encode the two dimensions of intensity and occurrence, which make up salient stressors (cf. previous section). However, not all studies reported these two dimensions together, and a mixed coding scheme was therefore needed. It was decided that intense and commonly occurring stressors (or, most intense and most prevalent stressors when numerous stressors were reported) would be counted as "occurrences" across studies, while also encoding, in the form of bold or underlined fonts (cf. note in Table 2), those stressors that appeared at least once among the top three intense stressors (i.e., among studies reporting this dimension). Thus, stressors with most occurrences and with intensity fonts can be described as salient adolescent stressors. Note that when both dimensions of intensity and occurrences were reported, the decision was to count as occurrences those stressors that were most intense but relatively common (i.e., $\geq 5 \%$ prevalence), to filter out very intense but non-representative stressors. Also, 3 studies did not report either of these dimensions (i.e., occurrence or intensity) but, for exhaustiveness, their reported stressors were registered on the dimension of occurrence (Byrne et al., 2007; Compas et al., 1987; de Anda et al., 2000).

Third, the studies differed with regards to their methods for pooling adolescent stressors (i.e., expert-based vs. adolescent-based approaches; see Table 1 and section Literature Search Strategy). Although both sources of information can be seen as complementary (i.e., adolescent sources filling in stressors overlooked by experts, and conversely), it is unclear whether these two sources are commensurate enough to be combined. A coding strategy was therefore needed to mark this difference in methods as well. To do so, the coding scheme differentiated the two sources in the registration of categories of stressors, first by providing counts of occurrences based on both sources (plain font) and on the adolescent source only (italics; Table 2); and, second, by registering intense stressors according to expert (bold font) or adolescent sources (underlined font; Table 2). By using this scheme, the review data offer insights on those stressors for which adolescent- and expertbased approaches converge, and those that do not.

In sum, the encoding scheme enabled synthetizing the data while accounting for both qualitative (i.e., life domains, valence) and quantitative theoretical dimensions of stressors (i.e., occurrence, intensity). Although the dimension of frequency is not reported in the final systematic review (only two studies having reported this dimension; de Anda et al., 2000; Heubeck \& O'Sullivan, 1998), mean ratings of 


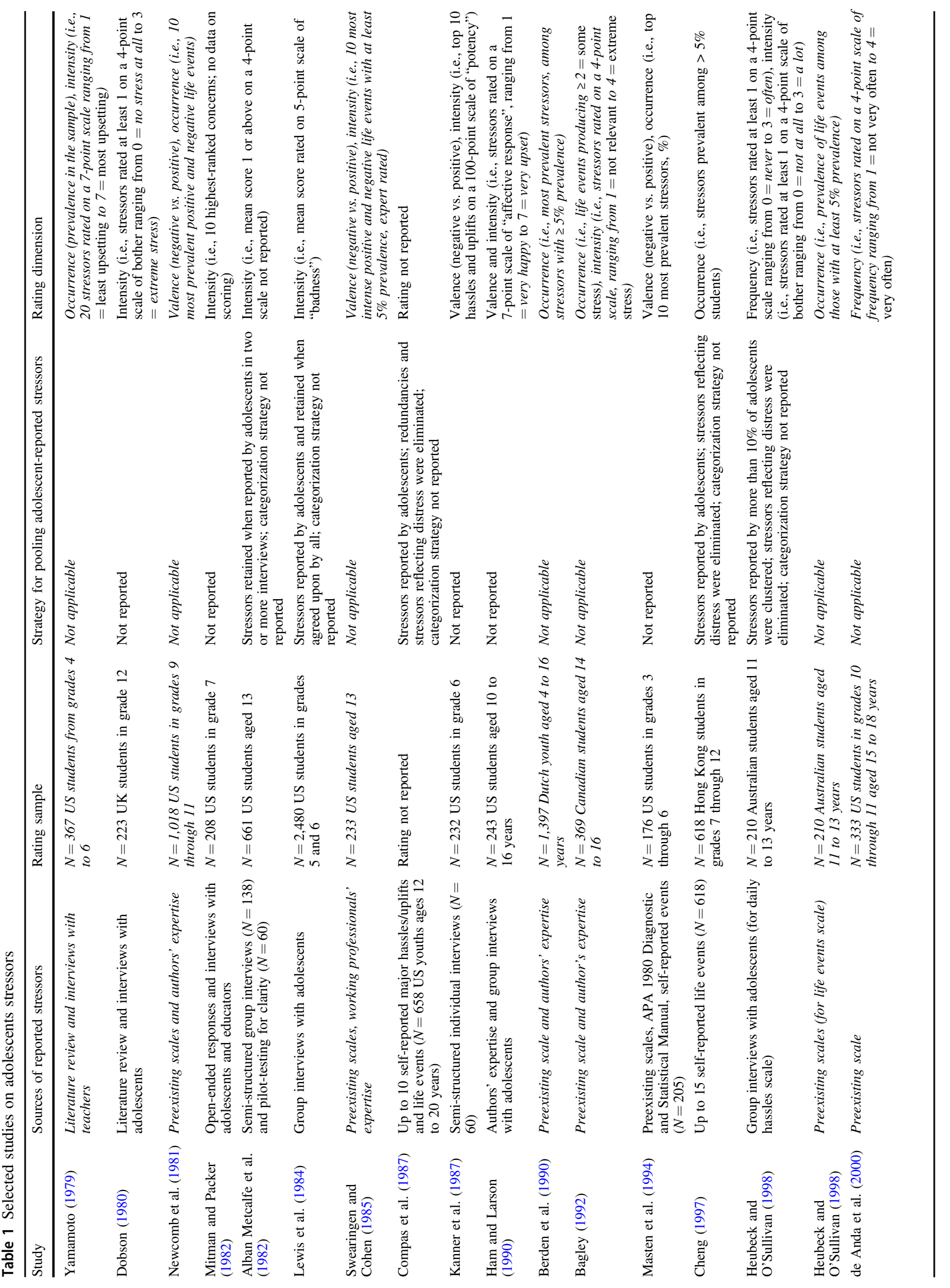




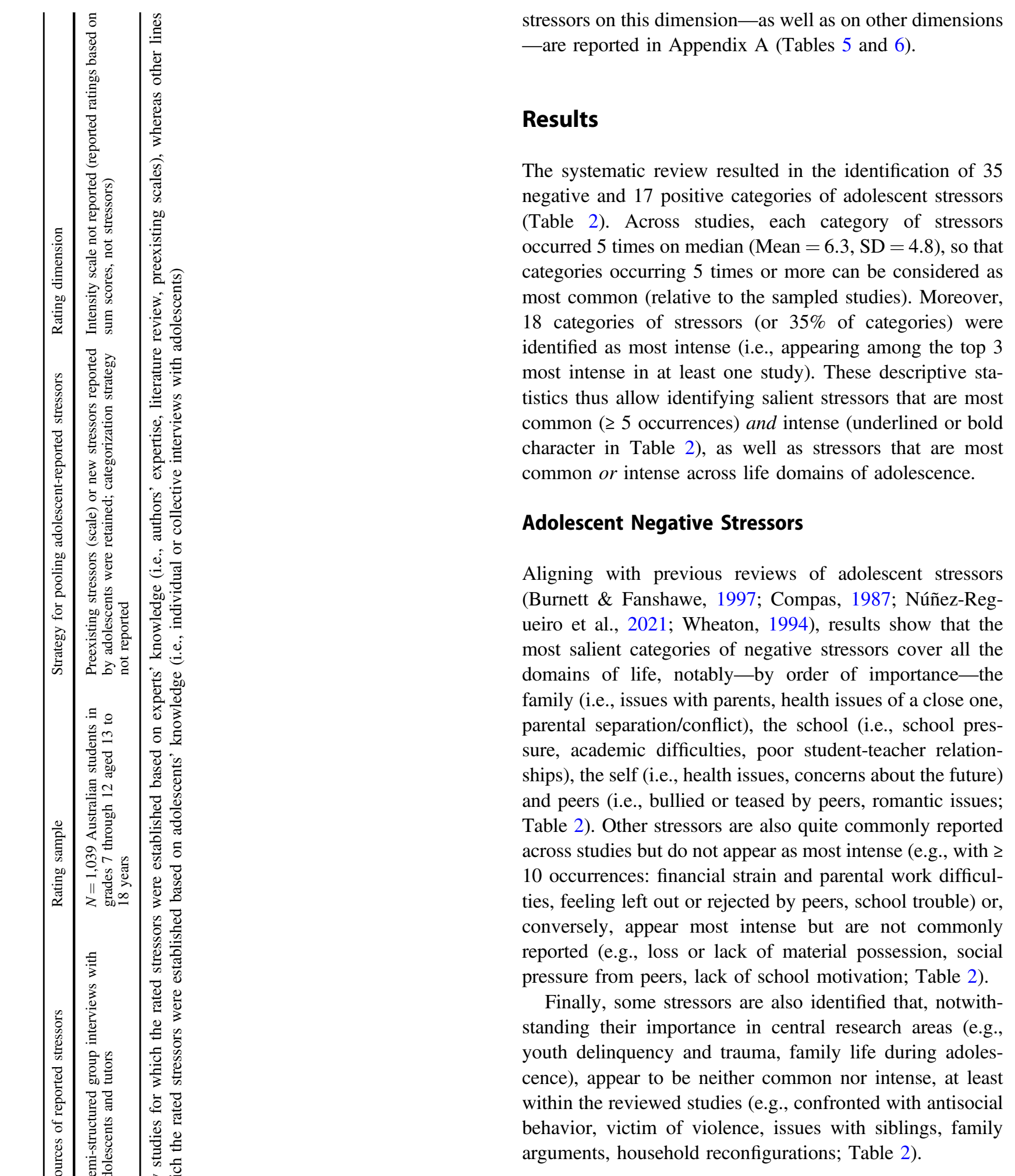

\section{Adolescent Positive Stressors}

By contrast with negative stressors, adolescent positive stressors have received limited attention in the literature, and therefore their occurrence and intensity are more difficult to establish. Nonetheless, some general observations 

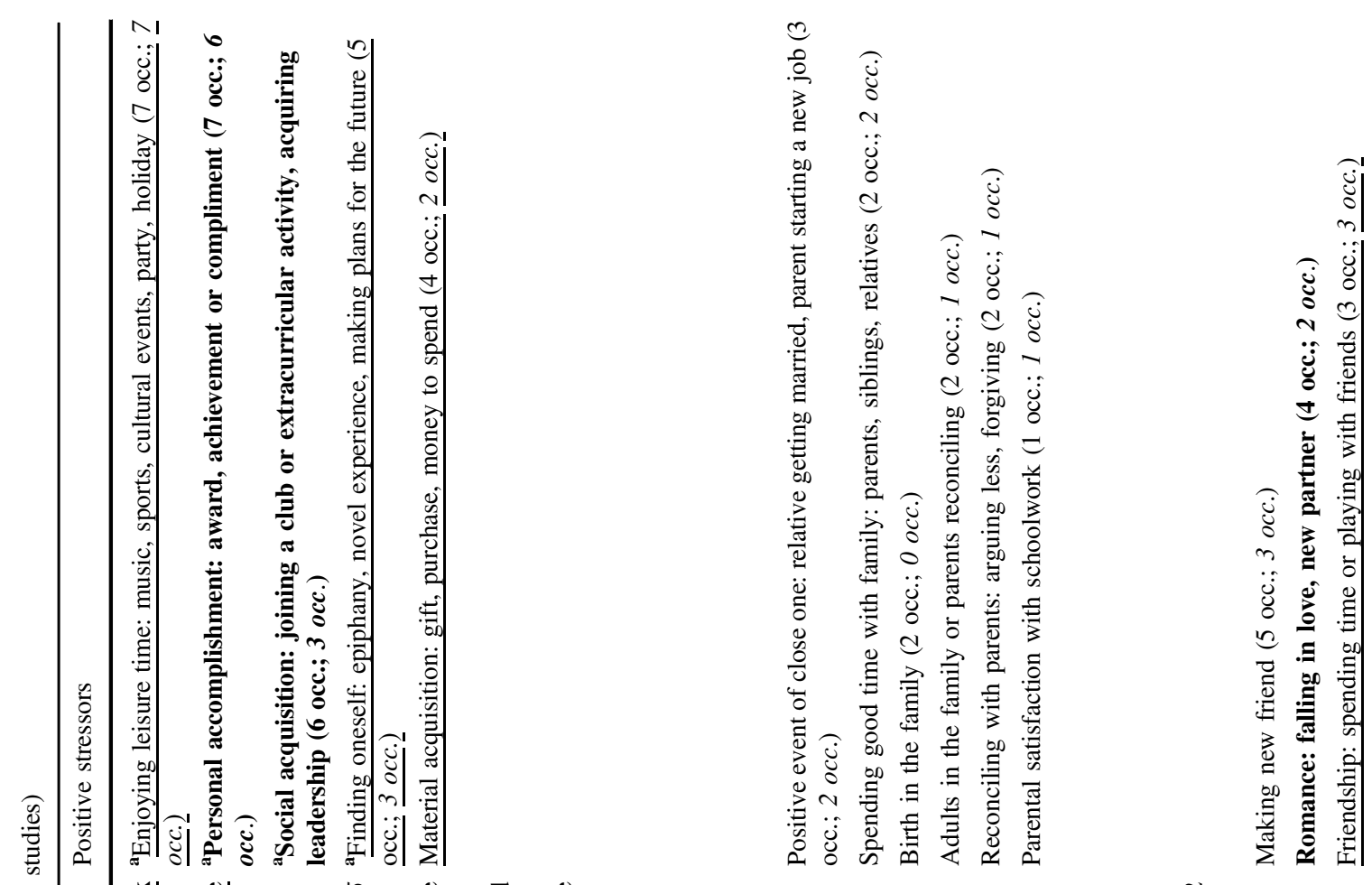

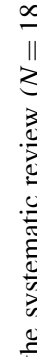

בี

(1)

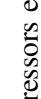

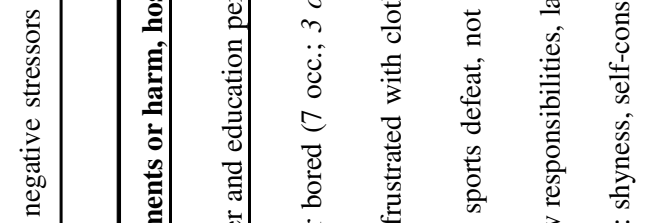

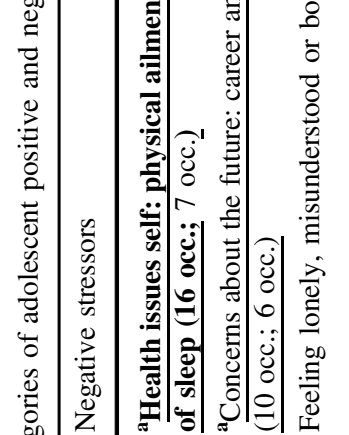

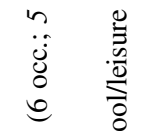

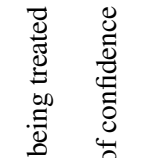

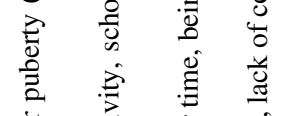

$\hat{j}$
$\dot{y}$
$\ddot{j}$
$\ddot{g}$

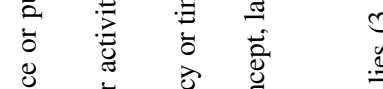

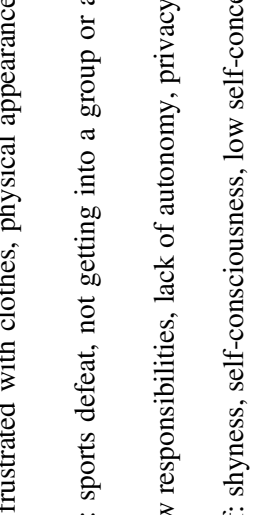

.

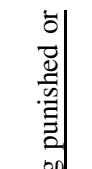

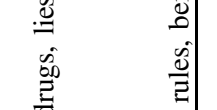

过

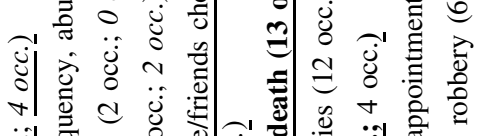

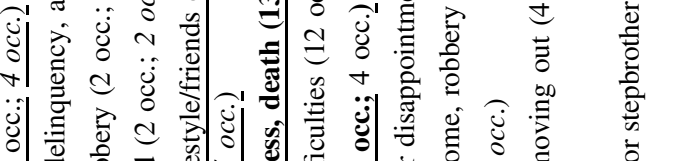

১)

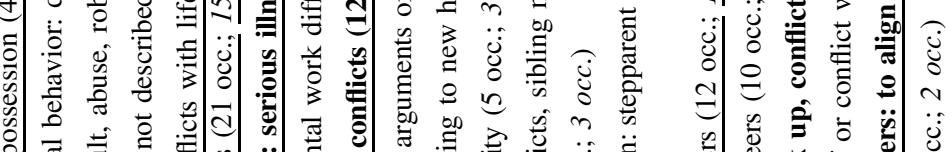

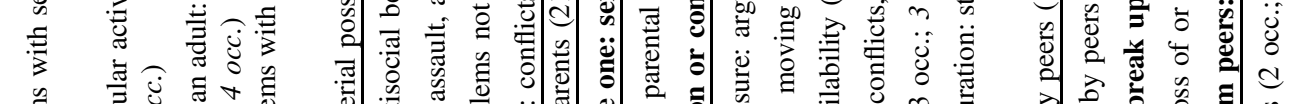

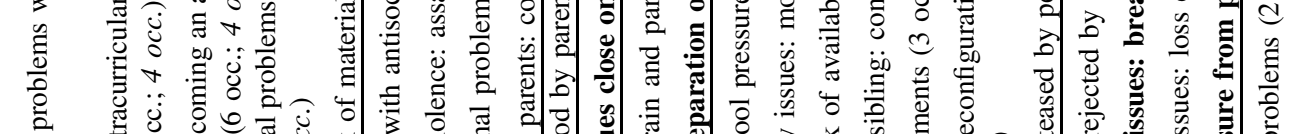

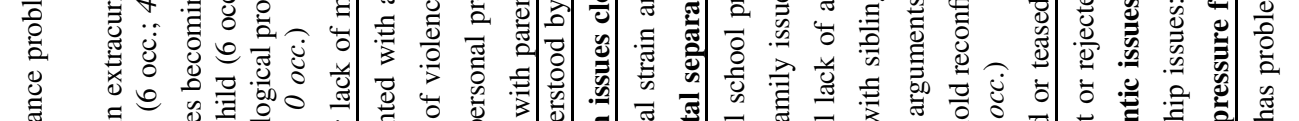

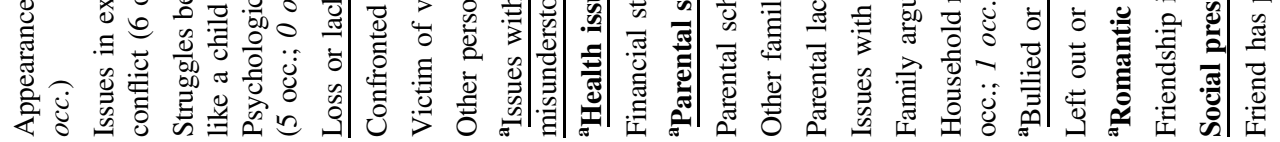

总

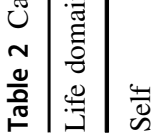


can be made. Using the same definitional criteria as before, the most salient positive stressors concern leisure time (e.g., music, sports, cultural events, parties), personal accomplishments (e.g., extracurricular award, achievement, or compliment), social acquisitions (e.g., joining a club or activity, acquiring a leadership position), finding oneself (epiphany, novel experiences, making plans for the future) and school achievement (good grades, passing of an exam, school award). Also, other positive stressors are commonly reported (e.g., making new friends) or particularly intense in terms of experience (e.g., material acquisitions, romance, friendship; Table 2). Notwithstanding these insights, the current evidence appears too meager to conclude on statuses of saliency (or intensity, occurrence) of other positive stressors, notably in the spheres of the family (e.g., positive event of a close one, spending good time with the family) or of school (e.g., good relationship with teacher).

\section{Discussion}

The present systematic review has shown that adolescent stressors are multidimensional and can be identified quite unequivocally across studies. In fact, it was found that most common and/or intense negative stressors identified in the systematic review aligned very well with themes of the "storm and stress" hypothesis that has been used to describe the period of adolescence, such as rebellion and resistance to adult authority, mood disruptions and emotional sensitivity, and norm-breaking or antisocial behaviors (Arnett, 1999). More precisely, the identified stressors concerned conflicts with adults and authority (issues with parents, poor student-teacher relationship, school trouble), struggling to fit in (left out or rejected by peers, conflicts with friends, social pressure from peers), not finding oneself (feeling lonely, misunderstood or bored, problems with personal appearance and self-concept, struggles becoming an adult), struggling with love (romantic issues), and harassment by peers (bullied or teased by peers). Moreover, complementary themes emerged that have received less attention in the stress literature, such as concerns about one's success in social evaluative processes at school (e.g., identified stressors of school pressure, academic difficulties; Banks \& Smyth, 2015; Låftman et al., 2013) or in the future (e.g., concerns about educational or career prospects; LeCompte \& Dworkin, 1991). Finally, the systematic review enabled the identification of salient positive stressors that, in many respects, appear to echo the themes of negative stressors, notably in relation to personal wellbeing (enjoying leisure time, finding oneself, personal accomplishments or acquisitions), peers (friendships, romance) and school (school achievement). More research is warranted in this domain to obtain a more definitive 
understanding of positive adolescent stressors. Also, notwithstanding the extensive coverage of the reviewed studies (i.e., more than 10,000 early to late adolescents from 6 different countries or nations), the methods used to extract stressors differed across studies (expert-based vs. adolescent-based, different categorization methods), as well as their scales for quantifying the dimensions of occurrence and intensity, which had to be adapted for the review. This might have introduced some biases in the quantification of saliency for each category of stressors. The above conclusions should therefore be explored more precisely in future research. The following content analysis of self-reported stressors, which explicitly measured these dimensions, can be regarded as a stepping-stone towards this type of explorative research.

\section{Study 2: A Content Analysis of Salient Adolescent Stressors}

The present study analyzes salient categories of adolescent stressors, based on written descriptions provided by a sample of high school students in France $(N=1,568)$. The first goal is to identify typical stressors reported by these adolescents in a replicable and objective manner using semi-automated, quantitative content analysis (Krippendorff, 2004; Silge \& Robinson, 2017). The second goal is to describe these typical stressors along the two dimensions of salience (i.e., intensity and occurrence), while also shedding light on complementary dimensions (i.e., valence, life domains, frequency). Based on previous reviews (Burnett \& Fanshawe, 1997; Compas, 1987; Núñez-Regueiro et al., 2021; Wheaton, 1994) and the findings from the first study, it is expected that adolescents will report stressors across multiple domains of life (Hypothesis $1-\mathrm{H} 1$ ), and that many of the most salient categories of stressors identified in Study 1 (i.e., negative stressors: health issues, concerns about the future, issues with parents, health issues of a close one, parental separation or conflicts, bullied or teased by peers, romantic issues, school pressure, academic difficulties, poor student-teacher relationship; positive stressors: enjoying leisure time, personal accomplishments, social acquisitions, finding oneself, school achievement) will also emerge as salient stressors in the present sample (Hypothesis 2- $\mathrm{H} 2$ ).

\section{Method}

\section{Participants}

Participants were French students in their first year of high school $(N=1,568$ adolescents, Mean age $=15.5$ years, $41.5 \%$ female adolescents, $54.9 \%$ in academic tracks), surveyed across 15 schools and 80 classes in the context of a longitudinal study on dropout processes (2014-2020). The longitudinal sample $(N=1,956)$ comprised both academic and vocational students and presented socio-demographic and academic characteristics that are statistically equivalent to those of the national population (Núñez-Regueiro \& Bressoux, 2021). However, the present sample was reduced to the 1,568 students who took the study survey at the middle $(n=1,355)$ and/or end $(n=1,163)$ of the first year of high school. Descriptive statistics show that nonrespondents (19\% of sample) were slightly older than respondents, had lower academic abilities and were overrepresented in the vocational track (all differences significant, $p<0.001)$, but did not differ significantly from respondents at the $5 \%$ threshold in terms of gender, social background or grade retentions prior to high school (descriptive statistics reported in Appendix B, Table 7).

\section{Procedure}

On a voluntary basis, adolescents completed at school an online questionnaire measuring psychological constructs and socio-demographic or academic characteristics (111 items in total). At the end of the questionnaire, an openended section asked participants to describe in their own words four major events that occurred in the prior 2 months, and to rate them along dimensions of intensity $(1=$ mild; 2 =rather mild; $3=$ rather strong; $4=$ strong; $5=$ very strong $)$, valence $(1=$ positive $; 2=$ negative $)$, frequency $(1$ $=$ once $; 2=$ sometimes $; 3=$ often $; 4=$ very often $; 5=$ all the time), and domain of life ( $1=$ your person; $2=$ your family; $3=$ your friends; $4=$ your high school; $5=$ your society). In total, participants reported 3,590 events (i.e., 1,754 negative vs. 1,836 positive stressors) for which data on the dimensions was available.

\section{Semi-Automated Quantitative Content Analysis}

A semi-automated quantitative content analysis was conducted to reduce the self-reported stressors into coherent units of analysis. Quantitative content analysis can be defined as the numerical analysis of qualitative data using systematic procedures for decomposing the qualitative data (Kuckartz, 2014). The systematic procedures consisted here in reducing the sample of 3,590 texts reported by adolescents into recurring meaningful units of analysis or "tokens", following semi-automated text analysis (Silge \& Robinson, 2017). To facilitate the identification of tokens, non-informative words (articles, prepositions, etc.) were automatically removed using the package quanteda (Benoit et al., 2018) via $\mathrm{R}$ software (R Core Team, 2016). Next, words that were semantically equivalent in the present context were manually recoded to a single expression (e.g., 
nouns "father" or "mother" were recoded as "parent"; adjectives "great", "awesome" were recoded as "good"), as well as words that were equivalent once the plural or gender concordance was removed (e.g., "friends" were recoded as "friend"). The final step consisted in automatically identifying tokens defined by recurring combinations of words or "collocations", also using quanteda. The two latter steps (i.e., manual recoding and identification of collocations) were conducted iteratively until redundancies disappeared in single words or collocations. Using quanteda, the 100 most frequently occurring tokens-either single words or collocations-were extracted, both for those reported as "positive" (100 tokens) and "negative" (100 tokens) in terms of valence. This resulted in a final set of unique tokens classified by their number of occurrences in the sample of texts (for an overview of final tokens, see Appendix B, Tables 8 and 9).

After the semi-automated text analysis, the identified tokens were described by computing their means and standard deviations on the dimensions of frequency and intensity reported by adolescents (cf. Procedure). To enhance the comparison with previous research (cf. Study 1), the tokens were grouped by using the categories from the systematic review or, in a minority of cases, into subcategories (e.g., tokens referring to various sports were grouped into the category of "Sport activity", instead of the previously identified general category of "Enjoying leisure time"). Finally, statistics for each category were computed by summing up the occurrences of its underlying tokens, and by computing weighted means and standard deviations of frequency and intensity (weights were based on the occurrences of each underlying token). A synthetic measure of "salience" was computed by multiplying categories' occurrences and intensity after reduction to a common scale (i.e., $\mathrm{SD}=1$ ).

\section{Results}

The text analysis and grouping of tokens resulted in 20 categories for negative stressors and 24 categories for positive stressors, which cumulated in 1,093 and 962 occurrences, respectively (cf. Tables 3 and 4). Some tokens consisted in non-words or words that could not be associated with specific categories of stressors out of context (e.g., "parent", "pain", "nothing", "problem"; $7.2 \%$ of occurrences overall), which were therefore not classified. Other problematic tokens concerned negative categories appearing among positive events (e.g., "health issues", "family conflict, divorce", "brawl"; $1.6 \%$ of occurrences), perhaps due to the omission of relevant contextual words that were not tokenized within collocations, such as words denoting a positive remission from or adjustment to
Table 3 Categories of negative stressors reported by high school students $(N=1,568)$

\begin{tabular}{|c|c|c|c|c|}
\hline Category & Salience & Occurrences & Intensity & Frequency \\
\hline Health issues self & 3.21 & 304 & $3.1(1.5)$ & $3.0(1.6)$ \\
\hline Family arguments & 1.76 & 172 & $3.0(1.6)$ & $3.0(1.6)$ \\
\hline $\begin{array}{l}\text { Health issues close } \\
\text { one }\end{array}$ & 1.45 & 121 & $3.5(1.4)$ & $2.1(1.3)$ \\
\hline Friendship issues ${ }^{\mathbf{a}}$ & 0.96 & 85 & $3.3(1.4)$ & $2.2(1.5)$ \\
\hline Romantic issues & 0.82 & 71 & $3.4(1.4)$ & $2.6(1.4)$ \\
\hline Other family issues ${ }^{\mathbf{a}}$ & 0.77 & 76 & $3.0(1.6)$ & 2.9 (1.6) \\
\hline Feeling stressed out & 0.74 & 63 & $3.4(1.4)$ & $3.4(1.3)$ \\
\hline Unclassified & 0.50 & 57 & $2.6(1.3)$ & $3.2(1.4)$ \\
\hline $\begin{array}{l}\text { Parental separation } \\
\text { or conflicts }\end{array}$ & 0.41 & 35 & $3.4(1.5)$ & $2.6(2.1)$ \\
\hline $\begin{array}{l}\text { Terrorist attack } \\
\text { (Charlie Hebdo) }\end{array}$ & 0.39 & 29 & $3.9(1.1)$ & $1.5(0.9)$ \\
\hline $\begin{array}{l}\text { Academic } \\
\text { difficulties }\end{array}$ & 0.29 & 25 & $3.4(1.2)$ & $2.9(1.6)$ \\
\hline Issues with sibling & 0.15 & 12 & $3.8(1.9)$ & $2.3(1.8)$ \\
\hline School pressure & 0.14 & 13 & $3.2(1.1)$ & $3.4(1.9)$ \\
\hline School trouble ${ }^{\mathbf{a}}$ & 0.10 & 9 & $3.2(1.2)$ & $2.3(1.2)$ \\
\hline $\begin{array}{l}\text { Poor student- } \\
\text { teacher relationship }\end{array}$ & 0.08 & 7 & $3.4(0.7)$ & $3.7(1.0)$ \\
\hline $\begin{array}{l}\text { Appearance } \\
\text { problems with self }^{\text {a }}\end{array}$ & 0.07 & 5 & $4.0(1.5)$ & $4.1(2.1)$ \\
\hline $\begin{array}{l}\text { Loss or lack of } \\
\text { material possession }\end{array}$ & 0.04 & 3 & $4.0(1.4)$ & $3.0(1.4)$ \\
\hline $\begin{array}{l}\text { Issues in } \\
\text { extracurricular } \\
\text { activity }^{\mathbf{a}}\end{array}$ & 0.03 & 2 & $4.0(1.4)$ & 1.0 (NA) \\
\hline $\begin{array}{l}\text { Confronted with } \\
\text { antisocial behavior }\end{array}$ & 0.02 & 2 & $3.5(2.1)$ & $3.5(2.1)$ \\
\hline Victim of violence & 0.02 & 2 & $2.5(2.1)$ & 1.0 (NA) \\
\hline
\end{tabular}

Categories in bold font correspond to salient stressors identified in Study 1. Tokens for each category of stressors (i.e., original single words or collocations) are reported in Appendix B (Table 8). Estimates (means and standard deviations) of intensity and frequency ratings are weighted based on the occurrences of each token, whereas occurrences are sum counts of occurrences of tokens within a category. Salience is computed by multiplying reduced scores of intensity and occurrences NA not available

${ }^{\mathrm{a} C}$ Categories also identified as most common or most intense in Study 1

negative stressors. Also, following stress researchers (Grant et al., 2004; Kohn \& Milrose, 1993; Masten et al., 1994), categories denoting psychological health ("feeling content", "feeling stressed out"; $3.9 \%$ of occurrences) were viewed as revealing distress or eustress, as opposed to actual stressors. After removal of the above problematic or "erroneous" categories, the remaining categories ( $87.2 \%$ of occurrences) provide a reliable pool to identify meaningful or "true" categories of adolescent stressors.

Aligning with $\mathrm{H} 1$, results show that adolescents reported negative and positive stressors from all the domains of life 
(i.e., self, family, peers, school; Tables 3 and 4). Incidentally, many students also reported a negative stressor from the domain of society at large (not covered in previous studies), namely the Charlie Hebdo attack (i.e., i.e., shooting that took place in Paris in 2015) (29 occurrences; Table 3). Aligning with $\mathrm{H} 2$, the meaningful categories of stressors reported by adolescents correspond, to a large extent, to the most salient categories of stressors identified in the systematic review (i.e., 11 out of 15 categories, identified by bold fonts in Tables 3 and 4), notably health issues of the self, health issues of a close one, romantic issues, parental separation or conflicts, academic difficulties, school pressure, poor student-teacher relationship, enjoying leisure time (i.e., subcategories "birthdays, parties, night out", "sport activity", "holidays, travels, outing", "cultural activity", "sports or cultural event"), finding oneself, school achievement, and personal accomplishment. In particular, many of the most salient stressors identified in Study 1 (i.e., 7 out 15) appear among the $50 \%$ most salient categories in the present sample, such as health issues of the self or of a close one, romantic issues, parental separation or conflicts, and academic difficulties for negative stressors (Table 3), and enjoying leisure time and finding oneself for positive stressors (Table 4). Also indirectly supporting H2, other highest ranked salient categories in the present sample concerned stressors which were previously identified in the systematic review as highly occurring or highly intense (i.e., the two dimensions of salience; 5 categories), such as friendship issues, other family issues (for negative stressors), romance, making new friends and friendship (for positive stressors). Previously identified positive stressors relative to the family were also found to be most salient in the present sample (i.e., birth in the family, spending good time with the family). Other salient stressors, not identified as such in the systematic review, concerned family arguments, the Charlie Hebdo attack, and receiving help at school (i.e., "help", "help_teacher"; Appendix B, Table 9). One salient stressor appeared ambiguous with regards to valence (e.g., "moving to a new home" appearing both among positive and negative stressors; Appendix B, Tables 8 and 9).

Finally, results from the content analysis also shed light on those stressors experienced "often" to "all the time" by adolescents (i.e., rated 3 or more on frequency, on average). More precisely, the most frequently experienced positive or negative stressors concerned experiences at school (poor student-teacher relationship, school pressure, school achievement), experiences at home (family arguments, having a pet), personal welfare (appearance problems with self, confronted with antisocial behavior, loss or lack of material possession, enjoying free time) and peers (romance, friendship, making new friends).
Table 4 Categories of positive stressors reported by high school students $(N=1,568)$

\begin{tabular}{|c|c|c|c|c|}
\hline Category & Salience & Occurrences & Intensity & Frequency \\
\hline Romance $^{\mathrm{a}}$ & 3.77 & 273 & $3.1(1.6)$ & $3.0(1.6)$ \\
\hline $\begin{array}{l}\text { Birthdays, parties, } \\
\text { night out }\end{array}$ & 1.50 & 96 & $3.5(1.3)$ & $2.3(1.4)$ \\
\hline Sport activity $^{b}$ & 1.37 & 83 & $3.7(1.2)$ & $3.4(1.4)$ \\
\hline Unclassified & 1.35 & 91 & $3.3(1.5)$ & $3.0(1.6)$ \\
\hline Moving to new home & 0.78 & 58 & $3.0(1.6)$ & $2.8(1.7)$ \\
\hline Making new friend ${ }^{\mathbf{a}}$ & 0.69 & 48 & $3.2(1.5)$ & $3.0(1.5)$ \\
\hline Birth in the family & 0.63 & 44 & $3.2(1.5)$ & $2.4(1.7)$ \\
\hline $\begin{array}{l}\text { Holidays, travels, } \\
\text { outing }^{\text {b }}\end{array}$ & 0.62 & 45 & $3.1(1.6)$ & $2.5(1.4)$ \\
\hline Friendship ${ }^{a}$ & 0.54 & 36 & $3.3(1.6)$ & $3.3(1.2)$ \\
\hline $\begin{array}{l}\text { Spending good time } \\
\text { with family }\end{array}$ & 0.41 & 26 & $3.5(1.3)$ & $2.8(1.5)$ \\
\hline Feeling content & 0.31 & 18 & $3.9(1.2)$ & $3.2(1.7)$ \\
\hline Health issues & 0.29 & 22 & $2.9(1.3)$ & $2.3(1.1)$ \\
\hline $\begin{array}{l}\text { Receiving help } \\
\text { at school }\end{array}$ & 0.26 & 19 & $3.1(1.6)$ & $3.2(1.5)$ \\
\hline Cultural activity $^{\mathbf{b}}$ & 0.23 & 12 & $4.2(1.2)$ & $2.9(2.1)$ \\
\hline $\begin{array}{l}\text { Sports or cultural } \\
\text { event }\end{array}$ & 0.22 & 11 & $4.5(0.9)$ & $2.5(0.9)$ \\
\hline Finding oneself & 0.21 & 13 & $3.6(1.3)$ & $1.8(1.0)$ \\
\hline Enjoying simple things & 0.20 & 15 & $2.9(1.3)$ & $4.0(1.1)$ \\
\hline School achievement & 0.17 & 11 & $3.5(1.3)$ & $3.0(1.6)$ \\
\hline $\begin{array}{l}\text { High school (courses, } \\
\text { boarding school) }\end{array}$ & 0.15 & 10 & $3.5(1.0)$ & $3.0(1.6)$ \\
\hline $\begin{array}{l}\text { Personal } \\
\text { accomplishment }\end{array}$ & 0.12 & 9 & $3.0(1.3)$ & $2.6(2.1)$ \\
\hline $\begin{array}{l}\text { Family conflict, } \\
\text { parental separation }\end{array}$ & 0.11 & 8 & $3.0(1.5)$ & $2.0(1.1)$ \\
\hline $\begin{array}{l}\text { Shopping (material } \\
\text { acquisition) }^{\mathbf{a}}\end{array}$ & 0.11 & 7 & $3.4(1.3)$ & $2.0(1.0)$ \\
\hline Having a pet & 0.08 & 4 & $4.5(0.7)$ & $3.0(2.0)$ \\
\hline Brawl & 0.03 & 3 & 2.0 (NA) & $2.5(0.7)$ \\
\hline
\end{tabular}

Categories in bold font correspond to salient stressors identified in Study 1. Tokens for each category of stressors (i.e., original single words or collocations) are reported in Appendix B (Table 9). Estimates (means and standard deviations) of intensity and frequency ratings are weighted based on the occurrences of each token, whereas occurrences are sum counts of occurrences of tokens within a category. Salience is computed by multiplying reduced scores of intensity and occurrences

$N A$ not available

${ }^{\mathrm{a} C}$ Categories also identified as most common or most intense in Study 1 bSub-categories corresponding to the category "Enjoying leisure time" in Study 1

\section{Discussion}

The present content analysis combined semi-automated text analysis and dimensional ratings to retrieve and characterize the categories of stressors that were typically reported by adolescents (i.e., dimension of occurrence, estimated by frequencies across adolescent writings) as well as experienced as intense (i.e., dimension of intensity, rated by adolescents). Overall, the analytic strategy appeared efficient for $87 \%$ of self-reports (vs. $13 \%$ unclassified selfreports) and offered coherent results. Aligning with 
previous studies (Burnett \& Fanshawe, 1997; Compas, 1987; Núñez-Regueiro et al., 2021; Wheaton, 1994) and Study 1 , the findings validated the hypotheses that adolescents reported stressors from multiple domains of life (H1) and that most salient stressors identified in the literaturei.e., according to the systematic review of Study 1-also appeared as salient stressors in the present sample of high school students (H2). More specifically, this was true for categories of positive or negative stressors concerning the self (negative: health issues of the self; positive: enjoying leisure time, finding oneself, personal accomplishment), the family (negative: health issues of a close one, parental separation or conflicts), peers (negative: romantic issues; positive: romance) and school (negative: academic difficulties, school trouble, poor student-teacher relationship; positive: school achievement). Similarly, many of the most salient stressors in the present sample corresponded to frequently occurring or highly intense stressors in Study 1 (negative stressors: friendship issues, other family issues; positive stressors: making new friends, friendship, birth in the family, spending good time with the family). New salient stressors were also identified for negative stressors (family arguments, terrorist attack) and positive stressors (receiving help at school). Notwithstanding their coherence with the literature, these results need to be confirmed in replication studies using a similar methodology (content analysis and dimensional ratings), notably to test the robustness of the identification strategy and the relative salience of each category of stressors in other national contexts than France.

\section{General Discussion}

Stressful life events and conditions model significantly the physical, psychological and social changes that individuals experience during adolescence. As such, adolescent stressors can provide a general framework for unifying theories across disciplines such as education, psychopathology and criminology. However, studies in the field have failed to provide a clear picture of adolescent stressors, due to a lack of consistency in analytical methods (e.g., in terms of scales, dimensional ratings) but also to a lack of focus on this descriptive goal, both in empirical studies and in literature reviews. Describing typical adolescent stressors can nevertheless contribute to identify those events or conditions that are most relevant to include in measurement methods developed for adolescents, as well as those that explain developmental processes (e.g., youth profiles of social attachment or school dropout, offending behavior). In light of this research need, the present studies sought to inform on the nature of stressors that adolescents generally experience in their daily lives. This required elaborating an analytical framework to characterize stressors according to multiple dimensions and gathering evidence from two kinds of data, that is, cumulative data from previous studies (Study 1) and adolescent-reported textual data (Study 2).

\section{Findings on Salient Stressors of Adolescence}

This research enabled the identification of salient adolescent stressors relevant to the domains of the self, the family, peers and school, which are commonly encountered by adolescents and which are experienced as intense as well. The systematic review of Study 1 and the content analysis of Study 2 resulted in the identification of 12 salient negative stressors, 9 of which converged across studies. More specifically, these stressors related to challenges with regards to personal or significant other's welfare (i.e., health issues of the self, health issues of a close one, parental separation or conflicts), social relationships (i.e., issues with parents, family issues or arguments, friendship issues, romantic issues, bullied or teased by peers, poor studentteacher relationships), and integrating society as a valued individual (i.e., concerns about the future, school pressure, academic difficulties).

Positive stressors have received less attention in the literature and were more difficult to establish in the systematic review of Study 1. Combining the evidence with the content analysis of Study 2 suggests, nevertheless, the existence of at least 11 salient positive stressors ( 7 of which converged across studies) that denoted opportunities for personal growth (e.g., enjoying leisure time, finding oneself, personal accomplishments, social acquisitions), academic motivation (school achievement, receiving help at school), social relationships with peers (e.g., romance, friendship, making new friends) and family identity (e.g., birth in the family, spending good time with the family). These demonstrate that, over and above negative experiences of "storm and stress" (Arnett, 1999), adolescence also provides positive experiences of "communion and growth" that may play a compensatory role to obtain more stable patterns of behavior in the long run, so as to reach a formative equilibrium of negative and positive life experiences upon entering adulthood.

To date, these results provide a comprehensive and theoretically coherent description of specific adolescent stressors. They bridge the gap between previous reviews on adolescent stressors measures, which focused on psychometric qualities (Burnett \& Fanshawe, 1997; Compas, 1987; Grant et al., 2004; Matheny et al., 1993; Newcomb et al., 1981; Núñez-Regueiro et al., 2021; Turner \& Wheaton, 1997), and preliminary findings that offered general views on the life domains covered by stressors scales (Burnett \& Fanshawe, 1997). 


\section{Implications for Research and Practice}

By establishing which stressors appear most salient during adolescence, the present results offer clear indications on which stressors might be relevant for methodologists seeking to develop more refined stressors scales. At present, measurement methods have privileged an exhaustive approach focused on measuring all potential sources of stress, which is very costly in terms of participant investment (e.g., answering 100-item checklists of stressors, taking hour-long interviews), thus increasing the risk for measurement error (Núñez-Regueiro et al., 2021). Instead, more efficient stressors scales can be envisaged (e.g., with 30 items or less) by focusing on stressors that have been shown to be most salient in the present studies and, possibly, in future research consolidating these findings.

This research can also open new avenues on the comprehension and treatment of adolescent stress processes. The fact that the content analysis of new qualitative data (Study 2, $N=1,568$ adolescents) obtained very similar results to the review of past quantitative and qualitative data (Study $1, N=18$ studies) is a strong indication that these salient stressors are robust and can probably be identified in other empirical samples as well. Researchers and practitioners might build on this hypothesis by using the identified categories of stressors as descriptive lenses to analyze, understand and act upon stress processes affecting youth and adolescents in other contexts than the ones covered here (i.e., Australia, Canada, Hong Kong, France, Netherlands, United Kingdom, United States of America). In particular, spin-off projects can be envisaged to establish links between the occurrence of specific categories of stressors and the emergence of specific adolescent profiles of school dropout (Lessard et al., 2008) or social attachment (Seiffge-Krenke, 2006). Likewise, the fact that many salient stressors have been established as most conducive to social deviance (e.g., bullied or teased by peers, poor student-teacher relationships, academic difficulties, issues with parents, family issues or arguments; Agnew \& Brezina, 2019) might explain the high incidence of deviant behavior associated with adolescent-limited offending, notably during the period of "maturity gap" as they transition to adult privileges and responsibilities (Moffitt, 2007). More precisely, adolescent-limited social deviance might result from coping with these negative stressors, as these have a strong social nature denoting inadequacy with regards to peers, parents, or society at large. As these stressors also depend on transient social roles (e.g., new forms of bonding or conflicts that contribute to identity-building towards adulthood), it is likely that the social deviance they facilitate resorbs upon stabilizing into more definitive adult roles, as has been observed for this kind of developmental profile (Moffitt, 2007).
These findings therefore contribute to the understanding of specific sources of stress that, given their salience, might be considered as strategic targets to curb adolescent psychological distress (Grant et al., 2014), school dropout (Dupéré et al., 2018) and offending behavior (Agnew \& Brezina, 2019). For example, practitioners could focus on developing interpersonal skills to deal with peer pressure and augment experiences of communion with peers (romance, friendship); on proposing mentorship programs to tackle academic difficulties and to improve studentteacher relationships; on improving social control (i.e., parental or teacher supervision) to reduce conflicts with authority and to limit situations of school bullying; and, for more efficiency, on interventions that combine all these approaches within an evaluative design (e.g., randomized control trials). Indeed, systemic interventions addressing both personal and social resources, such as Check and Connect programs for school students and their teachers (Janosz et al., 2019) or Multisystemic Therapy Programs for juvenile offenders and their families (Henggeler, 2011), have been shown to improve youth adaptation in the community (e.g., school engagement, academic achievement, educational aspirations, self-regulation strategies) and to decrease maladaptive behavior (e.g., recidivist offending, antisocial behavior, inattention, depressive feelings, school dropout). School-based programs have also been shown to be effective in reducing the amount of stress exposure itself, notably with regards to academic stressors (e.g., study pressure, workload, worry on grades; van Loon et al., 2020). Such programs can thus support adaptive coping as well as limit processes of stress proliferation (Pearlin \& Bierman, 2013).

\section{Limitations and Future Directions}

Of course, the above implications need to be understood in consideration of the limitations of the present studies, notably concerning the data and the analytic strategy. Concerning the data, the systematic review of Study 1 built on studies which were not designed to describe adolescent stressors, but which were used here as convenience data. As a result, the methodology used in the production of the data in these studies was often missing (e.g., no precise description of the method used to obtain exemplary stressors from interviews with adolescents) and based on noncommensurate measures (e.g., multiple dimensional ratings across studies). Future studies should therefore be designed to obtain complementary data using more explicit and systematic procedures for the extraction and quantification of self-reported stressors, as proposed in Study 2. Moreover, notwithstanding its analytical strengths, Study 2 used data that was limited in terms of external validity, being drawn from a sample of French adolescents showing very similar 
characteristics to the national population. Stronger results might be obtained in future studies by replicating Study 2 in other national contexts. That being said, these two limitations appear to be minor given the robustness of findings on salient stressors, as many of them appeared to converge across Study 1 and Study 2.

Concerning the limitations of the analytic strategy, the categories of stressors used in Studies 1 and 2 were developed in a view to reflect the state of the art among the reviewed studies, but complementary categories might be needed to provide a more complete picture of adolescent stressors. Moreover, research is needed to assess whether these categories are equally relevant across adolescent age groups (i.e., early, middle and late adolescents), and whether they can also be used among other youth (e.g., children, young adults). It might be hypothesized that the salience of stressors evolves as a function of changes specific to the individual (e.g., psychological need for autonomy, availability of coping resources) and to the context (e.g., social or academic demands), as has been illustrated in relation to school transitions (Crockett et al., 1989) and the person-environment transactions they imply (Kiuru et al., 2020). This, again, supports the need to integrate developmental theories within a common framework, so as to account for all potential stressors identified across separate disciplines.

\section{Conclusion}

Despite playing a crucial role in developmental processes, few studies have provided information on the nature of stressors experienced by adolescents, and none has systematically reviewed the evidence using coherent analytical dimensions. By proposing integrative dimensions, and by combining review data from existing studies with self-reported data from a sample of adolescents, the present research offered a comprehensive description of typical adolescent stressors across life domains. Focusing on salient stressors defined by their high rates of occurrence and intensity, the present findings converged in the identification of 12 negative stressors (i.e., health issues of the self, health issues of a close one, parental separation or conflicts, issues with parents, family issues or arguments, friendship issues, romantic issues, bullied or teased by peers, poor student-teacher relationships, concerns about the future, school pressure, academic difficulties) and 11 positive stressors (i.e., enjoying leisure time, finding oneself, personal accomplishments, social acquisitions, school achievement, receiving help at school, romance, friendship, making new friends, birth in the family, spending good time with the family) that can inform research and intervention programs within an interdisciplinary framework combining theories from developmental psychopathology, education and criminology. More precisely, understanding which stressors are most common and intense during adolescence can guide researchers and practitioners in the development of more efficient measurement tools for analytical or diagnostic purposes (e.g., shorter and more precise stressors scale), of more integrative and specific theoretical models to explain the emergence of youth profiles (attachment profiles, school dropout profiles) or the incidence of risky behavior during adolescence (e.g., social deviance), and of better targeted interventions programs aimed towards specific adolescent stressors. In this perspective, the present research enabled the identification of such stressors and revealed that, besides being a period of storm and stress, adolescence also provides experiences of communion and growth that have the potential to support identity formation towards adulthood. More research is nevertheless needed to consolidate these findings using more diversified samples and systematic analytical procedures to uncover potential etiological mechanisms involved in adolescent stress.

Acknowledgements Thanks are due to the headmasters, school counselors and teachers for their collaboration and help in the surveying process of Study 2.

Authors' Contributions F.N.R. participated in designing the review and content analysis (i.e., conceptualization, methodology, investigation), in collecting the data, and in writing the original draft of the manuscript; S.N.R. participated in designing the content analysis (i.e., conceptualization, methodology), in verifying and validating the review, and in reviewing and editing the draft. All authors read and approved the final manuscript.

Funding This research was supported partly by a doctoral grant to the first author (Appel à projets Grenoble Innovation Recherche "DESCOL").

\section{Compliance with Ethical Standards}

Conflict of Interest The authors declare no competing interests.

Informed Consent Informed consent was obtained from all participants of the study.

Publisher's note Springer Nature remains neutral with regard to jurisdictional claims in published maps and institutional affiliations.

\section{Appendix A - Notes on the Systematic Review}

Tables 5 and 6 


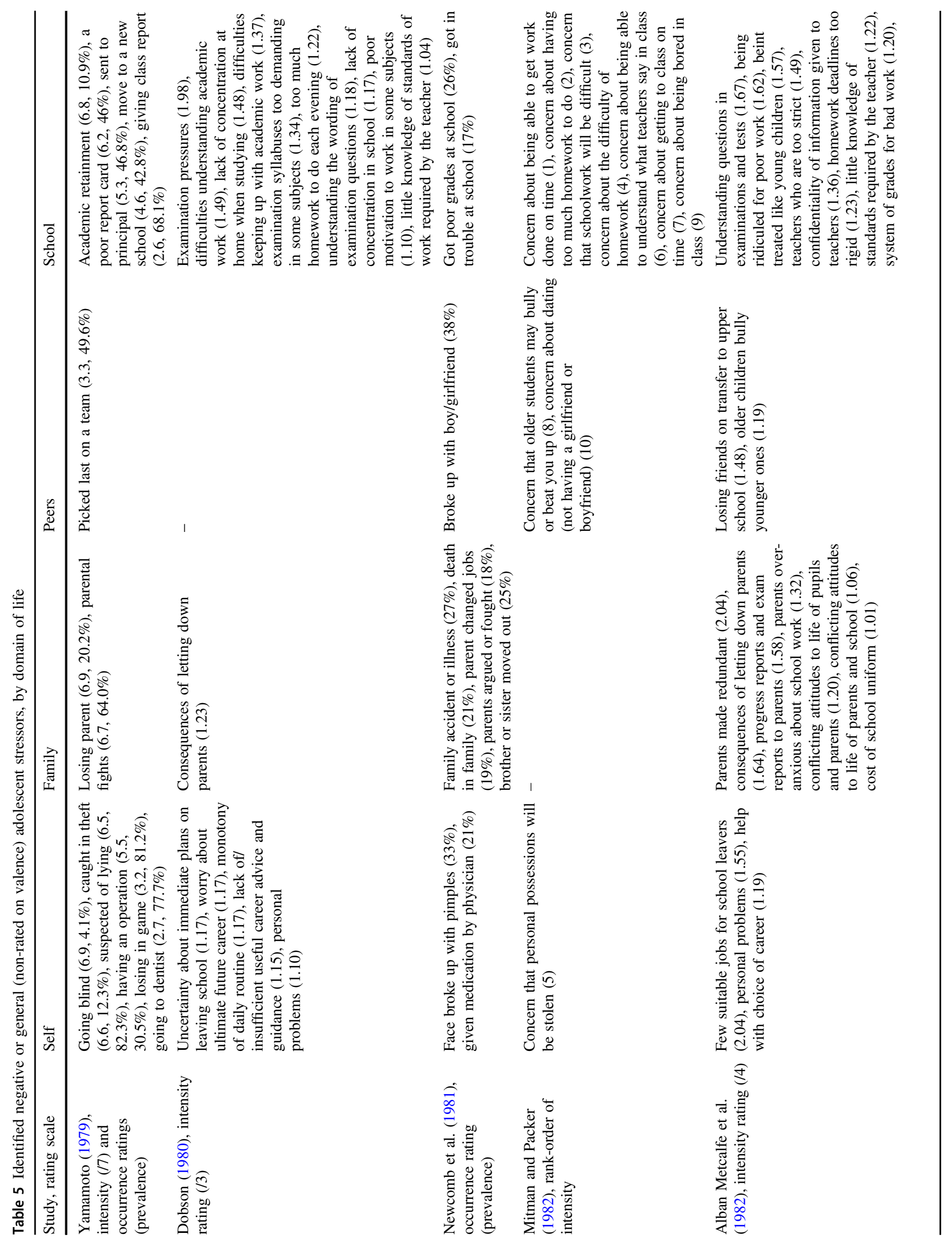




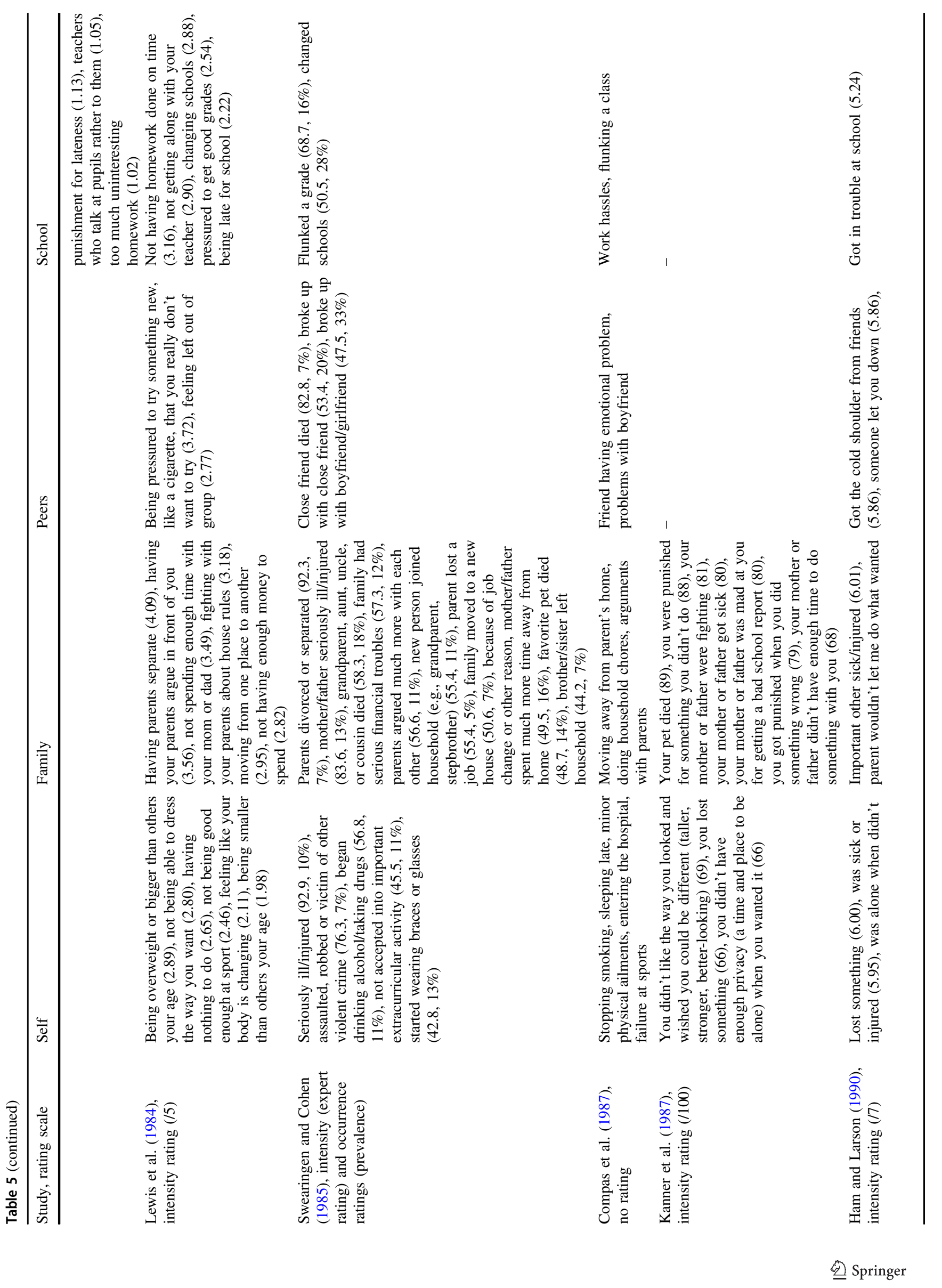




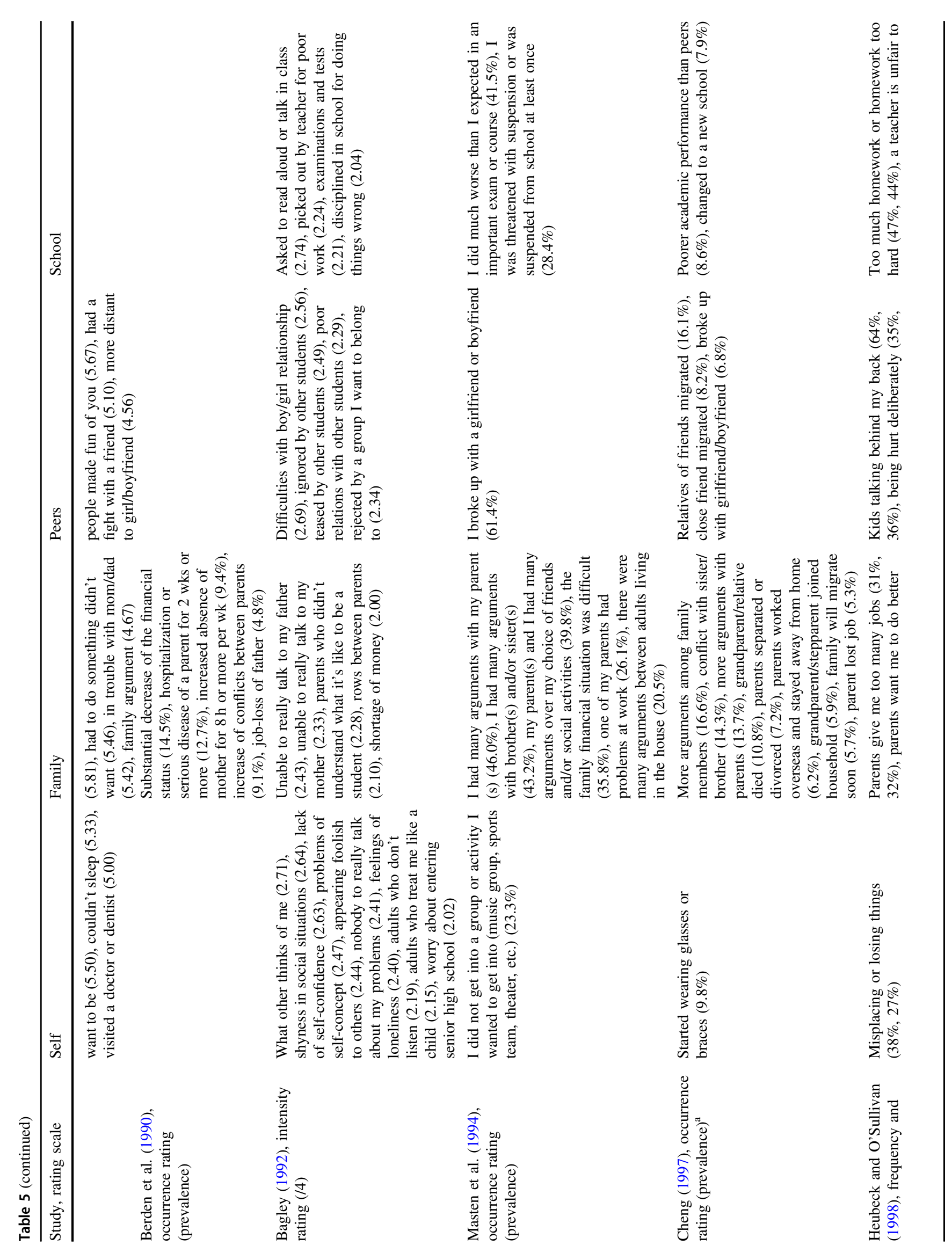




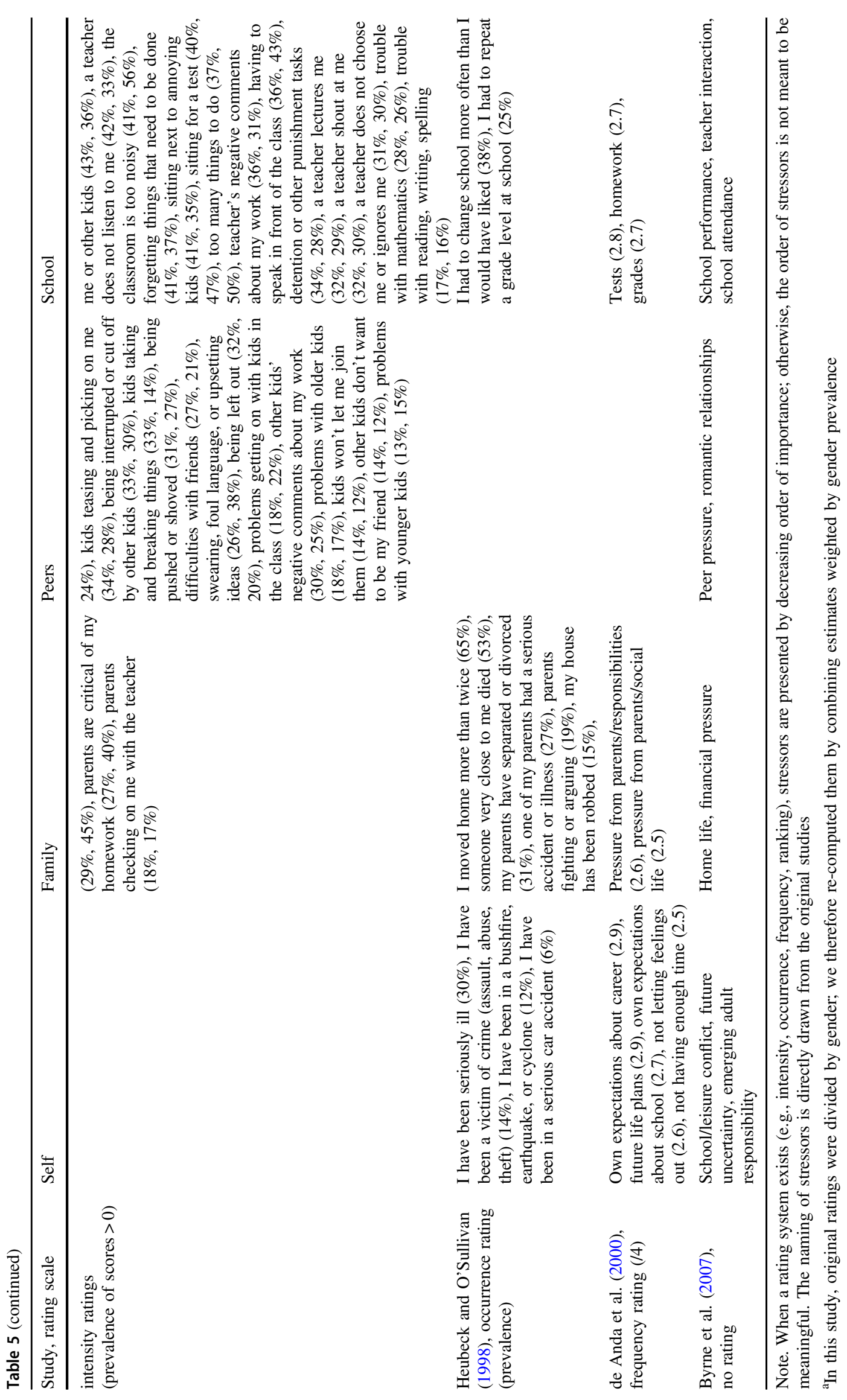




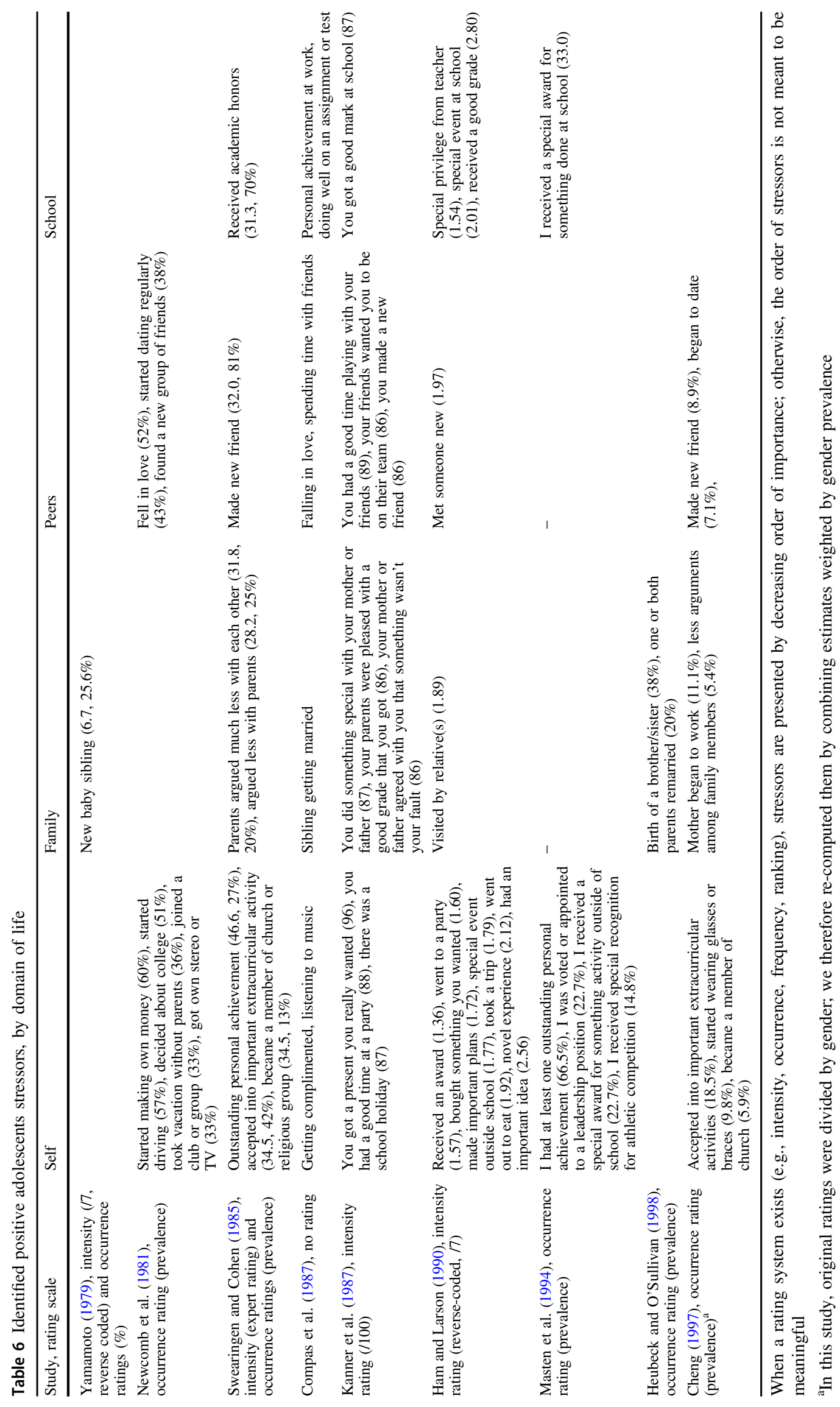




\section{Appendix B - Notes on Content Analysis}

Tables 7-9

Table 7 Characteristics of adolescents by survey missingness status ${ }^{\mathrm{a}}$

\begin{tabular}{llll}
\hline & Non-missing & Missing & $p$ value \\
\hline Age & $15.5(0.71)$ & $15.7 * * *(0.76)$ & 0.001 \\
\% Female adolescents & 41.5 & 45.9 & 0.134 \\
\% Father SES & & 42.0 & 0.351 \\
Low (ref.) & 38.7 & 34.3 \\
Intermediate & 33.7 & 11.6 \\
High & 12.1 & 12.1 \\
Very High & 15.4 & 16.5 \\
\% Repeated grade (primary school) & 14.0 & 25.0 \\
\% Repeated grade (middle school) & 21.2 & $10.5(3.13)$ \\
Academic ability (middle school national exam, /20) & $11.5 * * *(2.59)$ & 38.9 \\
\% Academic track (vs. vocational track) & $54.9^{* * *}$ & 0.249 \\
\hline
\end{tabular}

$N=1,956$ high school students (388 missing on the survey). Standard deviations appear in parentheses

${ }^{a}$ Differences are tested for overall significance with t-tests and odds ratios. Significance levels are indicated on the largest number

$\dagger p<0.10 ; * p<0.05 ; * * p<0.01 ; * * * p<0.001$

Table 8 Tokens of categories of negative stressors reported by high school students

\begin{tabular}{|c|c|}
\hline Category & Tokens \\
\hline Health issues self & $\begin{array}{l}\text { soreness, shoulder_pain, phobia, operation, leg_pain, knee_problem, knee_pain, } \\
\text { insomnia, illness, health_problem, head_pain, flu, catching a cold, belly_pain, } \\
\text { back_problem, back_pain, ankle_pain, allergy }\end{array}$ \\
\hline Family arguments & family_argument \\
\hline Health issues close one & $\begin{array}{l}\text { serious_illness_parent, serious_illness_close one, serious_illness, parent_illness, } \\
\text { loss_family_member, loss_close one, injury, illness_parent, funeral, death_parent, } \\
\text { death_family_member, death_close one, cancer_parent, accident }\end{array}$ \\
\hline Friendship issues & $\begin{array}{l}\text { loss_friend, loss, friend_argument, friend, death_friend, death, } \\
\text { argument_between_friend }\end{array}$ \\
\hline Romantic issues & $\begin{array}{l}\text { sex, romantic_encounter, romantic_disappointment, romantic_argument, } \\
\text { romance_break up, love, break up, boyfriend_argument }\end{array}$ \\
\hline Other family issues & robbery, moving to new home, family_problem, family \\
\hline Feeling stressed out & tiredness, stress, sadness, feel_unhappy, depression, anger \\
\hline Unclassified & shit, problem, parent, pain, nothing_special, nothing, nonword, argument \\
\hline Parental separation or conflicts & separation, parent_separation, parent_argument, divorce_parent, divorce \\
\hline Terrorist attack (Charlie Hebdo) & terrorist attack, charlie_hebdo_attack, charlie_hebdo, charlie \\
\hline Academic difficulties & poor_grade, grade, drop_grade \\
\hline Issues with sibling & sibling_argument, sibling, loss_sibling \\
\hline School pressure & work, school, high school, exam, classes \\
\hline School trouble & tardiness, brawl, absenteeism \\
\hline Poor student-teacher relationship & fuck_spanish, argument_teacher \\
\hline Appearance problems self & ugly, acne \\
\hline $\begin{array}{l}\text { Loss or lack of material } \\
\text { possession }\end{array}$ & loss_phone \\
\hline Issues in extracurricular activity & rugby \\
\hline $\begin{array}{l}\text { Confronted with antisocial } \\
\text { behavior }\end{array}$ & lies \\
\hline Victim of violence & aggression \\
\hline
\end{tabular}

Tokens were extracted automatically as a function of single occurrences or collocations of words reported by adolescents. Collocations of words are represented by the concatenator " - " 
Table 9 Tokens of categories of positive stressors reported by high school students

\begin{tabular}{|c|c|}
\hline Category & Tokens \\
\hline Romance & $\begin{array}{l}\text { sex, romantic_relationship, romantic_encounter, relationship, love, } \\
\text { in love, girlfriend, falling_in_love, couple }\end{array}$ \\
\hline Birthdays, parties, night out & wedding, party, night out, new_year, christmas, birthday \\
\hline Sport activity & $\begin{array}{l}\text { training, sport, skying, rugby, parkour, motorcycle, match, football, } \\
\text { equitation, danse, bodybuilding, bicycle, basketball, athletics }\end{array}$ \\
\hline Unclassified & $\begin{array}{l}\text { work, truck, snow, sibling, routine, parent, nothing, nonword, life, } \\
\text { girl, encounter, argument }\end{array}$ \\
\hline Moving to new home & moving to new home \\
\hline Making new friend & new_friend, friendly_encounter \\
\hline Birth in the family & birth_cousin, birth, baby \\
\hline Holidays, travels, outing & outing, journey, holidays \\
\hline Friendship & reconciliation, friendship, friend \\
\hline Spending good time with family & reuniting_family, reuniting, family_encounter, family \\
\hline Feeling content & positive, joy, good, cool, blossoming \\
\hline Health issues & injury, illness, back pain \\
\hline Receiving help at school & help_teacher, help \\
\hline Cultural activity & tatoo, playstation, music, guitar, games, computer \\
\hline Sports or cultural event & show, Lyon_champion, concert, cinema, champion \\
\hline Finding oneself & reorientation, internship \\
\hline Enjoying simple things & sleep, play, good laugh, eat \\
\hline School achievement & good_grade \\
\hline $\begin{array}{l}\text { High school (courses, boarding } \\
\text { school) }\end{array}$ & high school, classes, boarding school \\
\hline $\begin{array}{l}\text { Personal accomplishment: award, } \\
\text { achievement or compliment }\end{array}$ & victory, highway code, driver's license \\
\hline Family conflict, divorce & family_argument, divorce \\
\hline Shopping & shopping, sales \\
\hline Having a pet & pet \\
\hline Brawl & brawl \\
\hline
\end{tabular}

Tokens were extracted automatically as a function of single occurrences or collocations of words reported by adolescents. Collocations of words are represented by the concatenator " _"

\section{References}

Agnew, R., \& Brezina, T. (2019). General strain theory. In M. D. Krohn, N. Hendrix, G. Penly Hall, \& A. J. Lizotte (Eds.), Handbook on Crime and Deviance (pp. 145-160). Springer International Publishing. https://doi.org/10.1007/978-3-03020779-3_8.

Agurto, Y. J. E., \& Muñoz, M. V. Á. (2015). Validación de una escala de estrés cotidiano en escolares chilenos. Revista de Psicología, 33(2), 364-385.

Alban Metcalfe, R. J., Dobson, C. B., Cook, A., \& Michaud, A. (1982). The construction, reliability and validity of a stress inventory for children. Educational Psychology, 2(1), 59-71. https://doi.org/10.1080/0144341820020106.

Aldwin, C. M. (2007). Stress, coping, and development: an integrative perspective (2nd ed.): Vol. XVI. Guilford Press.

Arksey, H., \& O'Malley, L. (2005). Scoping studies: towards a methodological framework. International Journal of Social Research Methodology: Theory \& Practice, 8(1), 19-32. https:// doi.org/10.1080/1364557032000119616.

Arnett, J. J. (1999). Adolescent storm and stress, reconsidered. American Psychologist, 54(5), 317-326.
Bagley, C. (1992). Development of an adolescent stress scale for use by school counsellors: construct validity in terms of depression, self-esteem and suicidal ideation. School Psychology International, 13(1), 31-49. https://doi.org/10.1177/0143034392131003.

Banks, J., \& Smyth, E. (2015). 'Your whole life depends on it': academic stress and high-stakes testing in Ireland. Journal of Youth Studies, 18 (5), 598-616. https://doi.org/10.1080/13676261.2014.992317.

Benoit, K., Watanabe, K., Wang, H., Nulty, P., Obeng, A., Müller, S., \& Matsuo, A. (2018). quanteda: An R package for the quantitative analysis of textual data. Journal of Open Source Software, 3 (30), 774 https://doi.org/10.21105/joss.00774.

Berden, G. F. M. G., Althaus, M., \& Verhulst, F. C. (1990). Major life events and changes in the behavioural functioning of children. Journal of Child Psychology and Psychiatry, 31(6), 949-959. https://doi.org/10.1111/j.1469-7610.1990.tb00836.x.

Branson, V., Dry, M. J., Palmer, E., \& Turnbull, D. (2019). The Adolescent Distress-Eustress Scale: development and validation. SAGE Open, 9(3), 2158244019865802 https://doi.org/10.1177/ 2158244019865802.

Burnett, P. C., \& Fanshawe, J. P. (1997). Measuring school-related stressors in adolescents. Journal of Youth and Adolescence, 26 (4), 415-428. https://doi.org/10.1023/A:1024529321194. 
Byrne, D. G., Davenport, S. C., \& Mazanov, J. (2007). Profiles of adolescent stress: the development of the adolescent stress questionnaire (ASQ). Journal of Adolescence, 30(3), 393-416. https://doi.org/10.1016/j.adolescence.2006.04.004.

Cheng, C. (1997). Assessment of major life events for Hong Kong adolescents: the Chinese adolescent life event scale. American Journal of Community Psychology, 25(1), 17-33. https://doi.org/ 10.1023/A:1024641723920.

Compas, B. E. (1987). Stress and life events during childhood and adolescence. Clinical Psychology Review, 7(3), 275-302. https:// doi.org/10.1016/0272-7358(87)90037-7.

Compas, B. E., Davis, G. E., Forsythe, C. J., \& Wagner, B. M. (1987). Assessment of major and daily stressful events during adolescence: the Adolescent Perceived Events Scale. Journal of Consulting and Clinical Psychology, 55(4), 534 https://doi.org/10. 1037/0022-006X.55.4.534.

Crockett, L. J., Petersen, A. C., Graber, J. A., Schulenberg, J. E., \& Ebata, A. (1989). School transitions and adjustment during early adolescence. The Journal of Early Adolescence, 9(3), 181-210.

de Anda, D., Baroni, S., Boskin, L., Buchwald, L., Morgan, J., Ow, J., Gold, J. S., \& Weiss, R. (2000). Stress, stressors and coping among high school students. Children and Youth Services Review, 22(6), 441-463. https://doi.org/10.1016/S0190-7409(00) 00096-7.

Dobson, C. B. (1980). Sources of sixth form stress. Journal of Adolescence, 3(1), 65-75. https://doi.org/10.1016/S0140-1971(80) 80013-3.

Dupéré, V., Dion, E., Leventhal, T., Archambault, I., Crosnoe, R., \& Janosz, M. (2018). High school dropout in proximal context: the triggering role of stressful life events. Child Development, 89(2), e107-e122. https://doi.org/10.1111/cdev.12792.

Dupéré, V., Leventhal, T., Dion, E., Crosnoe, R., Archambault, I., \& Janosz, M. (2015). Stressors and turning points in high school and dropout: a stress process, life course framework. Review of Educational Research, 85(4), 591-629. https://doi.org/10.3102/ 0034654314559845.

Grant, K. E., Compas, B. E., Thurm, A. E., McMahon, S. D., \& Gipson, P. Y. (2004). Stressors and child and adolescent psychopathology: measurement issues and prospective effects. Journal of Clinical Child and Adolescent Psychology, 33(2), 412-425. https://doi.org/10.1207/s15374424jccp3302_23.

Grant, K. E., McMahon, S. D., Carter, J. S., Carleton, R. A., Adam, E. K., \& Chen, E. (2014). The influence of stressors on the development of psychopathology. In M. Lewis \& K. D. Rudolph (Eds.), Handbook of Developmental Psychopathology (pp. 205-223). Springer US. https://doi.org/10.1007/978-1-46149608-3_11.

Ham, M., \& Larson, R. (1990). The cognitive moderation of daily stress in early adolescence. American Journal of Community Psychology, 18(4), 567-585. https://doi.org/10.1007/ BF00938060.

Henggeler, S. W. (2011). Efficacy studies to large-scale transport: the development and validation of multisystemic therapy programs. Annual Review of Clinical Psychology, 7(1), 351-381. https://doi. org/10.1146/annurev-clinpsy-032210-104615.

Heubeck, B., \& O'Sullivan, C. (1998). An exploration into the nature, frequency and impact of school hassles in the middle school years. Australian Psychologist, 33(2), 130-137. https://doi.org/ 10.1080/00050069808257394.

Janosz, M., Pascal, S., Archambault, I., Goulet, M., Galand, B., Blanchard, C., Hospel, V., Nault-Brière, F., \& Christenson, S. L. (2019). Implementing Check \& Connect: Lessons from two international effectiveness experiments. In J. A. Fredricks, A. L. Reschly, \& S. L. Christenson (Eds.), Handbook of Student Engagement Interventions (pp. 263-277). Academic Press. https://doi.org/10.1016/B978-0-12-813413-9.00018-8.
Kanner, A. D., Feldman, S. S., Weinberger, D. A., \& Ford, M. E. (1987). Uplifts, hassles, and adaptational outcomes in early adolescents. The Journal of Early Adolescence, 7(4), 371-394. https://doi.org/10.1177/0272431687074002.

Kiuru, N., Wang, M.-T., Salmela-Aro, K., Kannas, L., Ahonen, T., \& Hirvonen, R. (2020). Associations between adolescents' interpersonal relationships, school well-being, and academic achievement during educational transitions. Journal of Youth and Adolescence, 49(5), 1057-1072. https://doi.org/10.1007/s10964019-01184-y.

Kohn, P. M., \& Milrose, J. A. (1993). The inventory of high-school students' recent life experiences: a decontaminated measure of adolescents' hassles. Journal of Youth and Adolescence, 22(1), 43-55. https://doi.org/10.1007/BF01537903.

Krippendorff, K. (2004). Content analysis: an introduction to its methodology (2nd ed.). Sage Publications, Inc.

Kuckartz, U. (2014). Qualitative text analysis: a guide to methods, practice and using software. Sage Publications, Inc.

Låftman, S. B., Almquist, Y. B., \& Östberg, V. (2013). Students' accounts of school-performance stress: a qualitative analysis of a high-achieving setting in Stockholm, Sweden. Journal of Youth Studies, 16(7), 932-949. https://doi.org/10.1080/13676261.2013. 780126.

Lazarus, R. S., \& Folkman, S. (1984). Stress, appraisal, and coping. Springer Publishing Company.

LeCompte, M. D., \& Dworkin, A. G. (1991). Giving up on school: Student dropouts and teacher burnouts. ERIC. http://eric.ed. gov/?id=ED340809.

Lessard, A., Butler-Kisber, L., Fortin, L., Marcotte, D., Potvin, P., \& Royer, É. (2008). Shades of disengagement: high school dropouts speak out. Social Psychology of Education, 11(1), 25-42. https:// doi.org/10.1007/s11218-007-9033-z.

Lewis, C. E., Siegel, J. M., \& Lewis, M. A. (1984). Feeling bad: exploring sources of distress among pre-adolescent children. American Journal of Public Health, 74(2), 117-122. https://doi. org/10.2105/AJPH.74.2.117.

Masten, A. S., Neemann, J., \& Andenas, S. (1994). Life events and adjustment in adolescents: the significance of event independence, desirability, and chronicity. Journal of Research on Adolescence, 4(1), 71-97. https://doi.org/10.1207/s15327795jra 0401_5.

Matheny, K. B., Aycock, D. W., \& McCarthy, C. J. (1993). Stress in school-aged children and youth. Educational Psychology Review, 5(2), 109-134. https://doi.org/10.1007/BF01323156.

Mitman, A. L., \& Packer, M. J. (1982). Concerns of seventh-graders about their transition to junior high school. The Journal of Early Adolescence, 2(4), 319-338. https://doi.org/10.1177/ 027243168200200403.

Moffitt, T. E. (2007). A review of research on the taxonomy of lifecourse persistent versus adolescence-limited antisocial behavior. In A. T. Vazsonyi, D. J. Flannery, \& I. D. Waldman (Eds.), The Cambridge handbook of violent behavior and aggression (pp. 49-74). Cambridge University Press. https://doi.org/10.1017/ CBO9780511816840.004.

Moher, D., Liberati, A., Tetzlaff, J., Altman, D. G., \& Group, P. (2009). Preferred reporting items for systematic reviews and meta-analyses: the PRISMA statement. PLoS Med, 6(7), e1000097 https://doi.org/10.1371/journal.pmed.1000097.

Newcomb, M. D., Huba, G. J., \& Bentler, P. M. (1981). A multidimensional assessment of stressful life events among adolescents: derivation and correlates. Journal of Health and Social Behavior, 22(4), 400-415. https://doi.org/10.2307/2136681.

Núñez-Regueiro, F., Archambault, I., Bressoux, P., \& Nurra, C. (2021). Measuring stressors among children and adolescents: a scoping review 1956-2020. Adolescent Res Rev. https://doi.org/ 10.1007/s40894-021-00168-z. 
Núñez-Regueiro, F., \& Bressoux, P. (2021). Vocational education as an institutional factor of school dropout: a multidimensional approach. Manuscript Submitted for Publication.

Pearlin, L. I., \& Bierman, A. (2013). Current issues and future directions in research into the stress process. In C. S. Aneshensel, J. C. Phelan, \& A. Bierman (Eds.), Handbook of the sociology of mental health (pp. 325-340). Springer Netherlands.

R. Core Team. (2016). $R$ : a language and environment for statistical computing (3.6). R Foundations for Statistical Computing. https://www.R-project.org.

Romeo, R. D. (2013). The teenage brain: the stress response and the adolescent brain. Current Directions in Psychological Science, 22 (2), 140-145.

Sandberg, S., Rutter, M., Giles, S., Owen, A., Champion, L., Nicholls, J., Prior, V., McGuinness, D., \& Drinnan, D. (1993). Assessment of psychosocial experiences in childhood: methodological issues and some illustrative findings. Journal of Child Psychology and Psychiatry, 34(6), 879-897. https://doi.org/10.1111/j.1469-7610.1993. tb01096.x.

Seiffge-Krenke, I. (2006). Coping with relationship stressors: the impact of different working models of attachment and links to adaptation. Journal of Youth and Adolescence, 35(1), 24 https:// doi.org/10.1007/s10964-005-9015-4.

Silge, J., \& Robinson, D. (2017). Text mining with R: a tidy approach. O'Reilly Media, Inc.

Swearingen, E. M., \& Cohen, L. H. (1985). Measurement of adolescents' life events: the junior high life experiences survey. American Journal of Community Psychology, 13(1), 69-85. https://doi.org/10.1007/BF00923260.

Turner, R. J., \& Wheaton, B. (1997). Checklist measurement of stressful life events. In S. Cohen, R. C.. Kessler, \& Gordon, Lynn U. (Eds.), Measuring stress: a guide for health and social scientists (pp. 29-58). Oxford University Press. van Loon, A. W. G., Creemers, H. E., Beumer, W. Y., Okorn, A., Vogelaar, S., Saab, N., Miers, A. C., Westenberg, P. M., \& Asscher, J. J. (2020). Can schools reduce adolescent psychological stress? A multilevel meta-analysis of the effectiveness of school-based intervention programs. Journal of Youth and Adolescence, 49(6), 1127-1145. https://doi.org/10.1007/s10964-020-01201-5.

Wheaton, B. (1994). Sampling the stress universe. In W. R. Avison \& I. H. Gotlib (Eds.), Stress and mental health (pp. 77-114). Springer US. https://doi.org/10.1007/978-1-4899-1106-3_4.

Wu, K. K., \& Lam, D. J. (1993). The relationship between daily stress and health: replicating and extending previous findings. Psychology \& Health, 8(5), 329-344. https://doi.org/10.1080/ 08870449308401926.

Yamamoto, K. (1979). Children's ratings of the stressfulness of experiences. Developmental Psychology, 15(5), 581-582. https:// doi.org/10.1037/h0078090.

Fernando Núñez-Regueiro is a postdoctoral researcher in educational sciences at the Université Grenoble Alpes. His research investigates the effects of individual development and training structures on youth adaptation and inclusion in the educational and labor markets, notably structures developed for vocational education, teacher education and inclusive education.

Santiago Núñez-Regueiro is a research consultant in social sciences and a $\mathrm{PhD}$ candidate at the Université de Picardie. His research combines mixed methods to study institutions, policies and regulations in Development studies and socioeconomics. 